\title{
LSA SAF Meteosat FRP products - Part 2: Evaluation and demonstration for use in the Copernicus Atmosphere Monitoring Service (CAMS)
}

\author{
G. Roberts ${ }^{1}$, M. J. Wooster ${ }^{2,3}$, W. Xu ${ }^{2}$, P. H. Freeborn ${ }^{4}$, J.-J. Morcrette ${ }^{5}$, L. Jones ${ }^{5}$, A. Benedetti ${ }^{5}$, H. Jiangping ${ }^{2}$, \\ D. Fisher ${ }^{2}$, and J. W. Kaiser ${ }^{6}$ \\ ${ }^{1}$ Geography and Environment, University of Southampton, Southampton, UK \\ ${ }^{2}$ Department of Geography, Kings College London, London, UK \\ ${ }^{3}$ NERC National Centre for Earth Observation, UK \\ ${ }^{4}$ Fire Sciences Laboratory, Missoula, MT, USA \\ ${ }^{5}$ European Centre for Medium-Range Weather Forecasts, Reading, UK \\ ${ }^{6}$ Max Planck Institute for Chemistry, Mainz, Germany
}

Correspondence to: G. Roberts (g.j.roberts@ soton.ac.uk)

Received: 31 December 2014 - Published in Atmos. Chem. Phys. Discuss.: 12 June 2015

Revised: 2 October 2015 - Accepted: 23 October 2015 - Published: 30 November 2015

\begin{abstract}
Characterising the dynamics of landscape-scale wildfires at very high temporal resolutions is best achieved using observations from Earth Observation (EO) sensors mounted onboard geostationary satellites. As a result, a number of operational active fire products have been developed from the data of such sensors. An example of which are the Fire Radiative Power (FRP) products, the FRP-PIXEL and FRP-GRID products, generated by the Land Surface Analysis Satellite Applications Facility (LSA SAF) from imagery collected by the Spinning Enhanced Visible and Infrared Imager (SEVIRI) onboard the Meteosat Second Generation (MSG) series of geostationary EO satellites. The processing chain developed to deliver these FRP products detects SEVIRI pixels containing actively burning fires and characterises their FRP output across four geographic regions covering Europe, part of South America and Northern and Southern Africa. The FRP-PIXEL product contains the highest spatial and temporal resolution FRP data set, whilst the FRP-GRID product contains a spatio-temporal summary that includes bias adjustments for cloud cover and the nondetection of low FRP fire pixels. Here we evaluate these two products against active fire data collected by the Moderate Resolution Imaging Spectroradiometer (MODIS) and compare the results to those for three alternative active fire products derived from SEVIRI imagery. The FRP-PIXEL product is shown to detect a substantially greater number of ac-
\end{abstract}

tive fire pixels than do alternative SEVIRI-based products, and comparison to MODIS on a per-fire basis indicates a strong agreement and low bias in terms of FRP values. However, low FRP fire pixels remain undetected by SEVIRI, with errors of active fire pixel detection commission and omission compared to MODIS ranging between 9-13\% and 65$77 \%$ respectively in Africa. Higher errors of omission result in greater underestimation of regional FRP totals relative to those derived from simultaneously collected MODIS data, ranging from $35 \%$ over the Northern Africa region to $89 \%$ over the European region. High errors of active fire omission and FRP underestimation are found over Europe and South America and result from SEVIRI's larger pixel area over these regions. An advantage of using FRP for characterising wildfire emissions is the ability to do so very frequently and in near-real time (NRT). To illustrate the potential of this approach, wildfire fuel consumption rates derived from the SEVIRI FRP-PIXEL product are used to characterise smoke emissions of the 2007 "mega-fire" event focused on Peloponnese (Greece) and used within the European Centre for Medium-Range Weather Forecasting (ECMWF) Integrated Forecasting System (IFS) as a demonstration of what can be achieved when using geostationary active fire data within the Copernicus Atmosphere Monitoring Service (CAMS). Qualitative comparison of the modelled smoke plumes with MODIS optical imagery illustrates that the model captures 
the temporal and spatial dynamics of the plume very well, and that high temporal resolution emissions estimates such as those available from a geostationary orbit are important for capturing the sub-daily variability in smoke plume parameters such as aerosol optical depth (AOD), which are increasingly less well resolved using daily or coarser temporal resolution emissions data sets. Quantitative comparison of modelled AOD with coincident MODIS and AERONET (Aerosol Robotic Network) AOD indicates that the former is overestimated by $\sim 20-30 \%$, but captures the observed AOD dynamics with a high degree of fidelity. The case study highlights the potential of using geostationary FRP data to drive fire emissions estimates for use within atmospheric transport models such as those implemented in the Monitoring Atmospheric Composition and Climate (MACC) series of projects for the CAMS.

\section{Introduction}

\subsection{Biomass burning emissions and Meteosat SEVIRI FRP products from the LSA SAF}

Biomass burning emissions databases derived from Earth Observation (EO) satellite data, such as the widely used Global Fire Emissions Database (GFED; van der Werf et al., 2006, 2010), typically follow the approach proposed by Seiler and Crutzen (1980) and estimate fire emissions via the multiplication of burned area $\left(\mathrm{m}^{2}\right)$, fuel load $\left(\mathrm{kg} \mathrm{m}^{-2}\right)$ and combustion completeness (unitless, 0-1) estimates. Emissions databases developed in this manner have been widely applied to deliver wildfire emissions of trace gases and aerosols for use in atmospheric transport models (Mu et al., 2011; Tsyro et al., 2007). However, whilst excellent for many applications, some limitations of this "burned-area"based approach are that it works only after the fire event, cannot be applied in near-real time and has a relatively low temporal resolution that provides little or no information on the variability of the emissions during the fire itself. All of these may be limitations when modelling certain aspects of fire emissions transport and generally preclude use of the approach in real-time atmospheric monitoring or forecasting systems (Reid et al., 2004). The companion paper to this work, Wooster et al. (2015) describes the geostationary Meteosat SEVIRI (Spinning Enhanced Visible and Infrared Imager) Fire Radiative Power (FRP) products being generated operationally by the EUMETSAT Land Surface Analysis Satellite Applications Facility (LSA SAF; http://landsaf.meteo.pt/). This type of geostationary active fire product offers an alternative route to biomass burning emissions estimation based on assessments of the thermal energy being radiated away from fires, and it can do so in nearreal time with frequent updates whilst the fires are still burning, though there are also some limitations caused mainly by fires having too low a fire radiative power remaining unde- tectable with the relatively coarse spatial resolution SEVIRI observations (Roberts and Wooster, 2008). Whilst Wooster et al. (2015) describe the methodologies and algorithms used to produce the LSA SAF Meteosat FRP products, and their information characteristics, the purpose of the current work is to (i) provide a full evaluation of the product compared to other real-time active fire products derived from the same SEVIRI observations, (ii) to provide a product validation via comparisons to the widely used and higher spatial resolution (albeit lower temporal resolution) MODIS (Moderate Resolution Imaging Spectroradiometer) active fire detections, and (iii) to demonstrate how the product can be used as a high temporal resolution biomass burning emissions driver within a case study that exploits components of the prototype CAMS (http://www.copernicus-atmosphere.eu/)

\subsection{Satellite Earth Observation active fire products}

Active fire products that are based on detecting the thermal radiation being emitted by landscape scale fires have been available for over 3 decades from numerous polar orbiting and geostationary satellites (Prins and Menzel, 1994; Prins et al., 1998; Matson, 1981; Justice et al., 1998; Giglio, 2003). In addition to simple detection, Dozier (1981) first demonstrated the additional potential to estimate a fire's sub-pixel effective temperature and fractional area, and this approach has been applied in the Wildfire Automated Biomass Burning Algorithm (WFABBA) to data from the Geostationary Operational Environmental Satellite (GOES) for over 2 decades (Prins and Menzel, 1994). Building on this idea, the FRP route to characterising active fires and estimating wildfire emissions was first proposed by Kaufman et al. (1996). The FRP approach is based on the understanding that the amount of heat produced by burning a fixed mass of biomass is relatively invariant to vegetation type (Jenkins et al., 1998). By measuring the component of this "heat of combustion" that is radiated away from the surface, the amount of vegetation being burned per second can then be estimated (Wooster et al., 2003, 2005; Freeborn et al., 2008). An advantage of the FRP approach for estimating smoke emissions to the atmosphere is that it is based on a direct remotely sensed observation, and a large number of polar and geostationary satellite instruments have the requisite midwave infrared (MWIR) waveband required to estimate FRP using the MIR (middle infrared region) radiance approach of Wooster et al. (2003, 2005). The MODIS instruments onboard the Terra and Aqua satellites have been providing FRP measurements since 2000 and 2002 respectively (Kaufman et al., 1998; Giglio et al., 2003) and are currently supported by the Visible Infrared Imaging Radiometer Suite (VIIRS) onboard SuomiNPP (Suomi National Polar-orbiting Partnership; Csiszar et al., 2014) and the soon-to-be-launched Sea and Land Surface Temperature Radiometer (SLSTR) onboard Sentinel3 (Wooster et al., 2012). Geostationary instruments, such as the GOES imager (Xu et al., 2010), are also providing 
FRP measurements at much higher temporal resolution but at lower spatial resolution and coverage, and those from the Meteosat SEVIRI instrument (Wooster et al., 2015) are the target of the current work.

\subsection{Wildfire emissions data sets from FRP observations}

Information on the fuel consumption totals required to build wildfire emissions inventories have already been developed using FRP data derived from polar-orbiter (Vermote et al., 2009; Ellicott et al., 2009; Kaiser et al., 2012) and geostationary satellite EO data (Pereira et al., 2011; Roberts et al., 2011). A limitation associated with the former is their intermittent observation of the diurnal fire cycle, which needs to be characterised in order to estimate daily Fire Radiative Energy (FRE; the temporal integration of FRP). MODIS typically provides around four daily observations depending on latitude which, when accumulated over a sufficiently long time period, have been exploited to model the diurnal fire cycle and estimate total emissions over 8-day or longer periods (Vermote et al., 2009; Ellicott et al., 2009). Geostationary FRP data sets provide much higher observation frequencies and thus unparalleled data on the diurnal fire cycle (e.g. Roberts and Wooster, 2007; Roberts et al., 2009), and Zhang et al. (2012) illustrate one way such data can be used to develop a near-global biomass burning emissions data set at hourly type temporal resolutions. However, a limitation of geostationary data is their coarse spatial resolution, which results biases in regional-scale FRP and FRE due to the omission of small and/or low intensity wildfires (Roberts et al., 2005; Xu et al., 2010). Freeborn et al. (2009) addressed this issue by synthesising a "virtual" FRP product via the integration of both geostationary and polar-orbiter FRP data, maintaining the high temporal resolution of geostationary data whilst simultaneously adjusting them for the active fire detection biases using the higher spatial resolution MODIS measurements. Roberts et al. (2011) blended geostationary FRP data with MODIS-derived burned area information to meet a similar objective.

Perhaps the most obvious advantage FRP-based biomass burning emissions inventories offer over a burned-area-based inventory is their near-real-time capability, since the thermal radiation being emitted by the active fires is being sensed whilst the fire is actually burning, rather than somewhat after the event. As a result, FRP-derived emissions estimates are being increasingly applied to characterise wildfire emissions for use in near-real-time atmospheric transport models. Sofiev et al. (2009) use MODIS FRP measurements to characterise particulate matter (PM) emissions using the method proposed by Ichoku and Kaufmann (2005), and the dispersion of the resulting emissions are propagated using the System for Integrated modeLling of Atmospheric coMposition (SILAM) dispersion model. In this approach, the diurnal variation of emissions is specified as being $25 \%$ greater than the daily mean during the day and $25 \%$ less than the mean during the night. Kaiser et al. (2009b, 2012) developed the Global Fire Assimilation System (GFAS) to prescribe wildfire emissions for use in the CAMS, potentially calculating the FRP density emitted by actively burning fires $\left(\mathrm{mW} \mathrm{m}^{-2}\right)$ using a variety of FRP measurements from different spacecraft. However, in the NRT (near-real time) version of GFAS used currently, only FRP measurements from MODIS are used. The FRE density $\left(\mathrm{J} \mathrm{m}^{-2}\right)$ is estimated by temporally integrating the MODIS-derived FRP density using a Kalman filter. Most recently, Turquety et al. (2014) used SEVIRI FRP measurements from the LSA SAF products to prescribe the fire diurnal cycle for the APIFLAME European fire emissions model, and Baldassarre et al. (2015) used both the LSA SAF SEVIRI FRP products and other active fire products to simulate the emissions and emissions transport of a large fire in Turkey.

This paper provides a detailed evaluation of the Meteosat SEVIRI FRP products available from the LSA SAF, both the full resolution FRP-PIXEL product and the reduced resolution FRP-GRID product, both available in near-real time and in archived form (http://landsaf.meteo.pt/), and provides a detailed example of their use in characterising wildfire emissions and their atmospheric transport at high temporal resolution. Section 2 provides a brief product summary, and readers are referred to the companion paper (Wooster et al., 2015) for a more detailed description of the algorithms used to derive the information from the raw SEVIRI level 1.5 observations. Section 3 describes a detailed intercomparison of the LSA SAF SEVIRI FRP-PIXEL product with both the MODIS active fire products (Giglio et al., 2003) and three alternative active fire products also derived from SEVIRI observations: the WFABBA (Prins et al., 1998), Fire Detection and Monitoring (FDeM; Amraoui et al., 2010) and Active Fire Monitoring (FIR) products (Joro et al., 2008). Section 4 evaluates the specific performance of the spatiotemporal summary "FRP-GRID" product available from the LSA SAF, which incorporates statistical adjustments for SEVIRI's regional FRP biases, whilst Sect. 5 describes use of the FRP-PIXEL product for parameterising wildfire emissions at high temporal resolution within the ECMWF (European Centre for Medium-Range Weather Forecasting) Integrated Forecasting System (IFS) atmospheric chemistry and transport model that is used to deliver the CAMS (http: //www.copernicus-atmosphere.eu/).

\section{Meteosat SEVIRI FRP products from the EUMETSAT LSA SAF}

SEVIRI onboard the Meteosat Second Generation (MSG) series of satellites acquires observations every 15 min over Earth's disk centred on western Africa, including in MWIR and long-wave infrared (LWIR) wavebands. Data collected in these wavebands enables the detection of active fires using the type of algorithms detailed in Li et al. (2001), and 


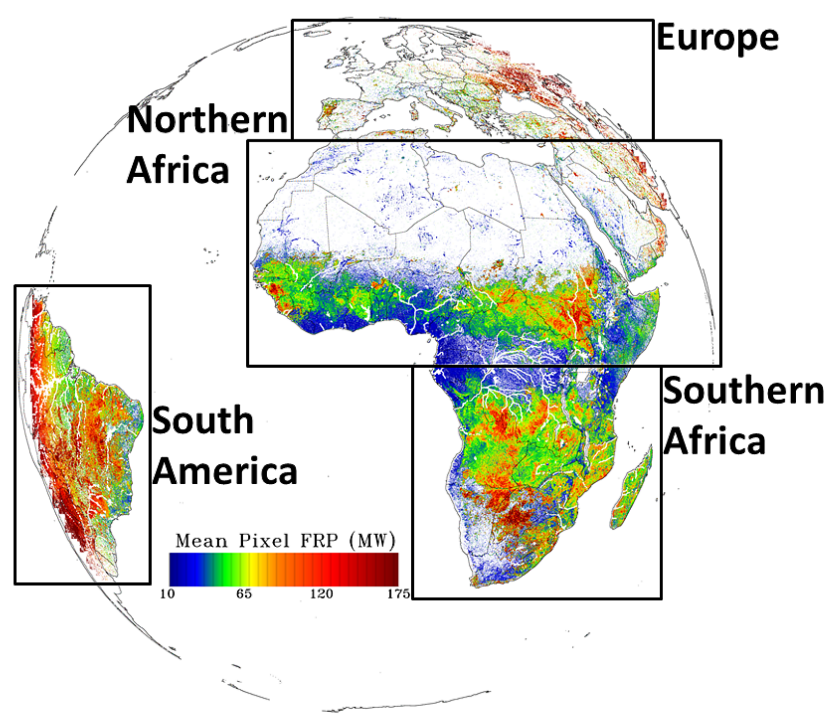

Figure 1. SEVIRI's imaging disk showing the mean per-pixel FRP (MW) seen in each SEVIRI pixel, calculated using all FRP-PIXEL products available between 2008 and 2013. Also indicated are the four geographic regions that LSA-SAF SEVIRI products are subset to.

this has been exploited for the development of a number of geostationary active fire products based on SEVIRI observations. One of these is the Meteosat SEVIRI FRP-PIXEL family of products that has been produced operationally since 2008 by the European Organisation for the Exploitation of Meteorological Satellites (EUMETSAT, 2007) LSA SAF (http://landsaf.meteo.pt). The LSA SAF Meteosat SEVIRI FRP product suite currently contains two components: (i) the FRP-PIXEL product which records active fire information at the full temporal and spatial resolution of SEVIRI, and (ii) the FRP-GRID product that provides a spatiotemporal summary of the FRP-PIXEL product, along with statistical adjustments for cloud cover and for the regional biases caused by the lowest FRP fires being undetectable with SEVIRI.

\subsection{FRP-PIXEL product summary}

The Level 2 FRP-PIXEL product provides information on the spatial location, thermal properties, atmospherically corrected FRP and uncertainty of pixels containing actively burning fires every 15 min over Europe, Northern and Southern Africa and part of South America (Fig. 1), based upon an extended version of the geostationary Fire Thermal Anomaly (FTA) active fire detection algorithm of Roberts and Wooster (2008) and a set of FRP estimation routines that are together fully detailed in Wooster et al. (2015). The structure of the FRP-PIXEL product is also detailed in Wooster et al. (2015), and follows the heritage of the MODIS active fire products (Giglio et al., 2003) but separated into two discrete files, (i) the FRP-PIXEL "Quality Product" file, a 2-D data set that provides information on the status of each SEVIRI pixel in the geographic region under study (e.g. whether it is a cloud, water, or land pixel, whether it has been classed as containing an active fire etc.; Wooster et al., 2015), and (ii) a smaller "List Product" file that provides detailed information of pixels in which active fires have been detected (e.g. including the pixel MWIR and LWIR brightness temperatures, FRP, FRP uncertainty, latitude and longitude, and some of the metrics derived during algorithm application such as background window size and estimated MWIR band atmospheric transmissivity).

\subsection{FRP-GRID product summary}

The Level 3 FRP-GRID product is a spatio-temporal summary of a series of FRP-PIXEL products. At the regional scale, the FRP-PIXEL product provides a minimum estimate of the FRP being emitted from landscape fires due to (i) the inability of SEVIRI to detect the lowest FRP active fire pixels (Roberts and Wooster, 2008; Freeborn et al., 2014b) and (ii) the fact that the assessment of the highest FRP fires suffer from some effects of pixel saturation and other SEVIRIspecific observation characteristics (Wooster et al., 2015). In order to try mitigate these impacts on regional FRP estimation, the LSA SAF processing chain generates the Level 3 FRP-GRID product by temporally accumulating active fire pixels and associated information from the maximum of four FRP-PIXEL products obtained each hour, grids this information within $5.0^{\circ}$ grid cells, and applies a set of regional bias adjustment factors. Wooster et al. (2015) describe the procedures in full, and an evaluation of the resulting product performance is presented in Sect. 4 herein.

\section{FRP-PIXEL product performance evaluation}

Here we validate the SEVIRI FRP products using MODIS active fire data. The relatively high spatial resolution of MODIS' active fire observations (1 km at nadir) and the high saturation temperature of its MWIR channel ( $\sim 500 \mathrm{~K})$, coupled with its better than daily availability from two platforms (the Terra and Aqua satellites), ensure that the MODIS active fire product (Kaufman et al., 1998; Giglio et al., 2003) is the standard against which geostationary active fire products are compared when performing product evaluations $(\mathrm{Xu}$ et al., 2010; Schroeder et al., 2014; Roberts and Wooster, 2014). Here we use near-simultaneously recorded Collection 5 MODIS active fire detections (MOD14 from Terra and MYD14 from Aqua) as the basis of our LSA SAF SEVIRI FRP product performance evaluations. For completeness, we also include a series of other SEVIRI active fire products, derived using different algorithms and methods to the LSA SAF FRP products, within the same comparison. 


\subsection{SEVIRI FRP-PIXEL and MODIS active fire product intercomparison}

\subsubsection{Methodology}

The FRP-PIXEL product is generated in separate files for the four LSA SAF geographic regions whose boundaries as shown in Fig. 1 (Wooster et al., 2015). We conducted the FRP-PIXEL product performance evaluation using 1 week of operational FRP-PIXEL data collected by Meteosat-9 in each of the LSA SAF regions, together with the matching MODIS MOD14 and MYD14 products. The FRP-PIXEL products of each region were derived from 672 separate SEVIRI imaging slots taken every $15 \mathrm{~min}$ over a $168 \mathrm{~h}$ period in 2008, with the timing of the products for each geographic region being that corresponding to its peak fire period; December in Northern Hemisphere Africa, and August in the remaining three regions. Freeborn et al. (2014b) previously performed an evaluation of the FRP-PIXEL product over the Central African Republic (CAR), finding that the products' active fire detection errors of commission reduced greatly (from 24 to $9 \%$ ) when the MODIS active fire detections were used as the independent data source and were limited to a $\pm 18.6^{\circ}$ scan angle. This is due to the increasing pixel area of MODIS with increasing scan angle, which results in MODIS itself showing progressively greater active fire errors of omission towards the scan edge (Freeborn et al., 2011). When comparing large-scan-angle MODIS data to active fire detections made from SEVIRI, it may well be that MODIS actually misses fires that the SEVIRI FRP-PIXEL product actually correctly detects; however, in the absence of any other information, a SEVIRI-to-MODIS performance evaluation would record this as a SEVIRI commission error. Therefore, to mitigate against the impact of MODIS' decreasing ability to detect low FRP pixels as MODIS scan angle increases, yet balance this with the need to maintain sufficient data in our intercomparison, MODIS observations are limited to those within a $\pm 30^{\circ}$ scan angle within which MODIS' pixel area increases up to a maximum of $1.7 \mathrm{~km}^{2}$ from the nadir $1 \mathrm{~km}^{2}$ size (Freeborn et al., 2011). For each LSA SAF geographic region we compared the active fire detections made by MODIS within this scan angle limit to the active fire pixels present in the FRP-PIXEL product subsets covering the same area and collected at the closest matching time (generally this will be within $\sim 6 \mathrm{~min}$ of the MODIS overpass). To deal with the differing MODIS and SEVIRI pixel sizes, we remapped the MODIS active fire data to SEVIRI's imaging grid. SEVIRI's per-pixel point spread function (PSF) at the sub-satellite point extends more than $5 \mathrm{~km}$ radially from the pixel centre (Wooster et al., 2015), so following the approach of Freeborn et al. (2014b) we evaluated active fire detection performance using the presence of an active fire pixel within a $3 \times 3$ pixel window centred on the active fire pixel under investigation within this grid as a matched detection. For SEVIRI errors of commission, we searched for the presence of a matching MODIS pixel for each SEVIRI active fire pixel studied, whilst the reverse analysis was conducted for SEVIRI errors of omission.

When undertaking the SEVIRI-to-MODIS FRP intercomparison, this was conducted on a "per fire" basis by clustering the MODIS and SEVIRI per-pixel FRP measurements for the same fire into "fire pixel clusters" on the basis of spatial closeness (e.g. Zhukov et al., 2006; Roberts and Wooster; 2008; Xu et al., 2011). The MODIS FRP measurements were derived using the same MIR radiance approach to FRP derivation as is used for SEVIRI (Wooster et al., 2005, 2015), and as will be employed in the forthcoming Collection 6 MODIS active fire products (L. Giglio, personal communication, 2014). We atmospherically corrected these MODIS FRP estimates using the same procedure applied when generating the FRP-PIXEL product, detailed in Wooster et al. (2015), based on an atmospheric transmission lookup table (LUT) developed using the MODTRAN5 and RTMOM atmospheric radiative transfer models (Berk et al., 2005; Govaerts, 2006) and ECMWF forecasts of total water column vapour (interpolated from an original spatial and temporal resolution of $0.5^{\circ}$ and $3 \mathrm{~h}$ ). Generally, the adjustment for the MWIR atmospheric transmission made to the SEVIRI FRP data was larger than that for MODIS, because the SEVIRI MWIR spectral band used in FRP derivation is significantly wider than that of MODIS and extends into spectral regions having much lower atmospheric transmission (Wooster et al., 2015).

\subsubsection{Results}

The results of our SEVIRI-to-MODIS per-fire active fire detection intercomparison are detailed in Table 1, columns 3 and 4. Taking the Northern Africa (NAfr) LSA SAF region as the first example, it is the closest region to the Meteosat subsatellite point and therefore offers the highest degree of SEVIRI spatial detail and smallest pixel area. We find that $65 \%$ of MODIS' active fire detections made within this region had no corresponding SEVIRI-detected active fire within the closest matching (in time) FRP-PIXEL product file. This "active fire error of omission" rate is higher than the $54 \%$ found previously by Roberts and Wooster (2008) over the same geographic area but using the prototype SEVIRI FTA algorithm, a different period satellite (Meteosat- 8 ) and different time period. The reverse analysis showed that $9 \%$ of the Meteosat-9 FRP-PIXEL product active fire pixels had no matching MODIS active fire pixel, a very similar commission error to that found by Roberts and Wooster (2008) for the prototype SEVIRI FTA algorithm over the same Northern Africa region.

SEVIRI FRP-PIXEL product active fire detection performance metrics for the other three LSA SAF geographic regions are also shown in Table 1 and indicate a substantially increased active fire omission error in South America and Europe compared to the two African regions. This is in part 
Table 1. Performance characteristics of the LSA SAF Meteosat SEVIRI FRP-PIXEL product in the four LSA SAF geographical regions, as compared to the MODIS active fire products (Collection 5 MOD14 and MYD14) collected over the same area and at the same time. Errors of omission and commission with respect to MODIS were calculated on a per-fire-pixel basis as described in Sect. 3.1.1. The per-fire basis results (column 5) were obtained when comparing the total FRP retrieved from MODIS and SEVIRI for fires (defined as a spatially contiguous set of active fire pixels) detected by both sensors. The area-based results (column 6) were derived from comparison of the total FRP measured by all detected fires in a matching MODIS and SEVIRI image area and thus include the influence of non-detected low FRP fires by SEVIRI whilst the per-fire comparison results (column 5) do not.

\begin{tabular}{|c|c|c|c|c|c|}
\hline $\begin{array}{l}\text { LSA SAF } \\
\text { geographic } \\
\text { region }\end{array}$ & $\begin{array}{l}\text { Image dates } \\
(2008)\end{array}$ & $\begin{array}{l}\text { Active fire pixel } \\
\text { detection omission } \\
\text { error }(\%)\end{array}$ & $\begin{array}{c}\text { Active fire pixel } \\
\text { detection commission } \\
\text { error }(\%)\end{array}$ & $\begin{array}{l}\text { Slope of linear best-fit relationship } \\
\text { between SEVIRI-to-MODIS and } \\
\text { per-fire-based FRP measures }\end{array}$ & $\begin{array}{l}\text { Slope of linear best-fit relationship } \\
\text { between SEVIRI-to-MODIS and } \\
\text { area-based FRP measures }\end{array}$ \\
\hline Northern Africa & 1-8 Dec & 65 & 9 & 0.96 & 0.65 \\
\hline Southern Africa & 19-24 Aug & 77 & 13 & 0.97 & 0.53 \\
\hline South America & 14-24 Aug & 91 & 39 & 0.97 & 0.22 \\
\hline Europe & 9-17 Aug & 97 & 30 & 0.88 & 0.11 \\
\hline
\end{tabular}
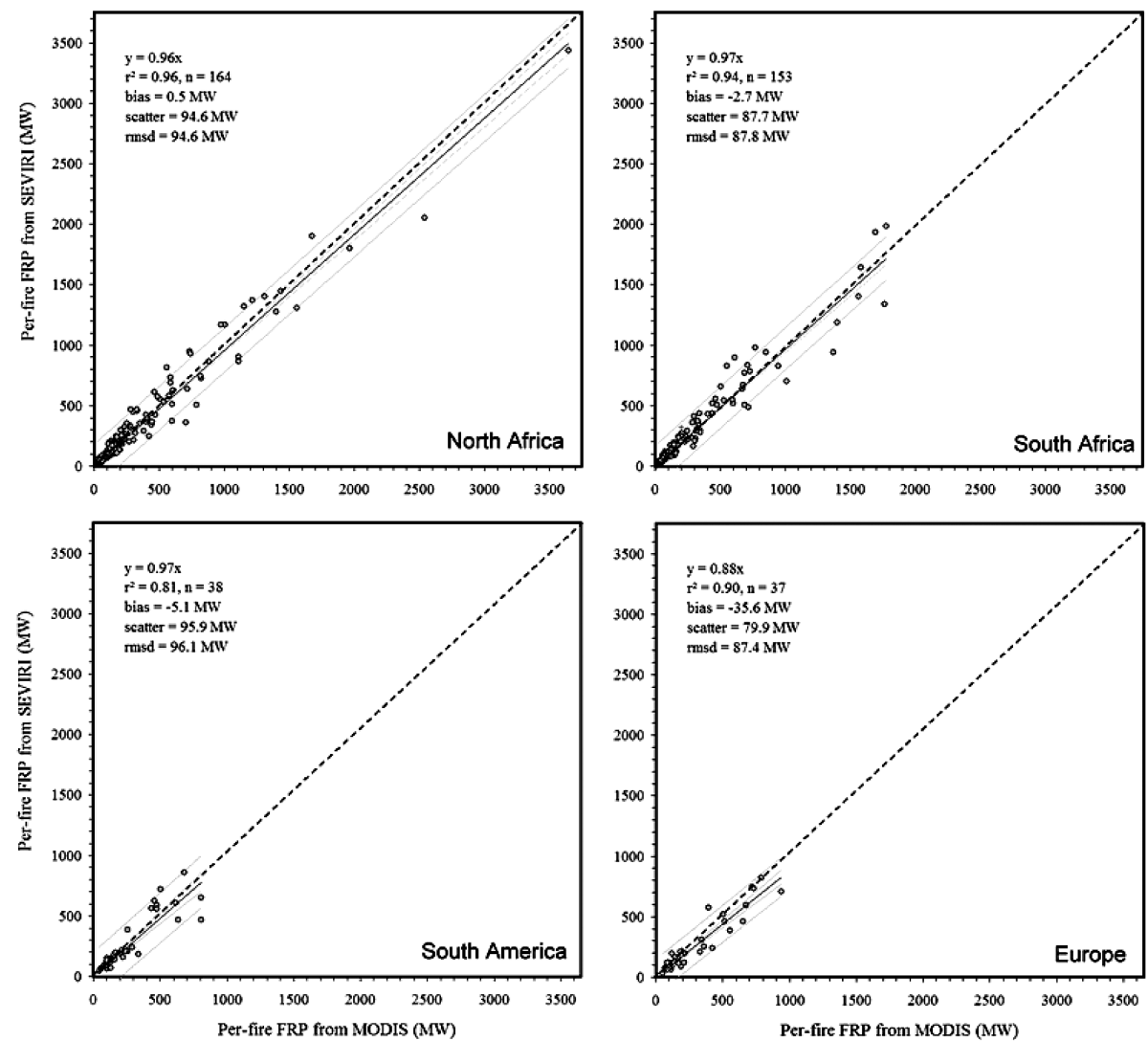

Figure 2. A comparison of per-fire FRP derived from SEVIRI and MODIS observations of fires observed near-simultaneously by each sensor during 1 week in each LSA SAF geographic region (Fig. 1). Fires are designated as contiguous clusters of active fire pixels. SEVIRI FRP is taken from the LSA SAF FRP-PIXEL product in each case and MODIS FRP is taken from the MOD14 product (Collection 5; Giglio et al., 2003). The most radiant fires were detected in the Northern Africa region (top left), and all regions are displayed on the same $x$ and $y$ axis scales for ease of comparison.

due to SEVIRI's increased pixel area and greater view zenith angle (and thus greater atmospheric attenuation) over the former two regions which are further from the Meteosat subsatellite point (SSP). South America and Europe have a mean view zenith angle of 59 and $54^{\circ}$ respectively and this significantly raises the minimum per-pixel FRP detection limit in these areas (Fig. 1), meaning a greater proportion of lower FRP landscape-scale fires fail to be detected by SEVIRI in comparison to the African regions.

Figure 2 and Table 1 (Column 5) present the results of the SEVIRI-to-MODIS per-fire FRP intercomparison. Again, taking Northern Africa as an example, on a per-fire basis 
there is a strong correlation between the FRP measures made by SEVIRI in this region and by MODIS (Fig. 2; top left) with over half $(53 \%)$ of the SEVIRI-to-MODIS matchups having an FRP difference of less than $20 \%$. In fact, a strong level of agreement exists for all regions in terms of a low FRP bias between the two data sets, but there is significant scatter. Overall, we find that $57 \%$ of the FRP-PIXEL products perfire FRP measures are within $20 \%$ of those of MODIS, and this level of agreement remains consistent even when limiting the comparison to fires with FRP of $\sim 50 \mathrm{MW}$ to ensure we focus on the FRP range where SEVIRI does not clearly underdetect active fires (e.g. Wooster et al., 2015). This suggests that the degree of variability seen between the nearsimultaneous measures of per-fire FRP provided by SEVIRI and MODIS is not driven only by active fire pixel errors of omission (e.g. by SEVIRI failing to detect some of the low FRP fire pixels making up a fire cluster) but may be impacted by other aspects of the FRP measurement process coming from

1. uncertainty in the ambient background signal used to calculate the FRP for each fire pixel with SEVIRI and MODIS data (Wooster et al., 2003, 2005, 2015; Zhukov et al., 2006);

2. the \pm 6 min time difference between corresponding MODIS and SEVIRI observations of the same fire, during which changes in the active fire characteristics that determine the fires FRP may occur;

3. the uncertainties present in the MODIS FRP measures coming from the sub-pixel location of the fire with respect to the sensor's instantaneous field of view, recently characterised by Freeborn et al. (2014c), and with SEVIRI also from certain image processing operations conducted during the production of SEVIRI level 1.5 data (Wooster et al., 2015);

4. effects of sensor saturation of SEVIRI's MWIR channel at high FRP fire pixels.

To place the magnitude of the scatter seen in Fig. 2 between the SEVIRI FRP-PIXEL product's FRP measures and those from the MODIS MOD14 and MYD14 products into context, during the recent Freeborn et al. (2014c) study, multiple MODIS FRP measurements of the same fires made almost simultaneously ( $\ll 1 \mathrm{~s}$ difference) in consecutive MODIS scans were compared and some large scan-to-scan differences were found. An approximately normally distributed percentage difference between the two FRP measures, with a mean close to zero but a standard deviation of $26.6 \%$, was determined from a large data set of such matchups (Freeborn et al., 2014c). Further investigation showed that the scan-toscan differences were largely controlled by the differing subpixel location of the fire within the different MODIS scans, a subject previously indicated as potentially significant with regard to FRP observations made by the BIRD (Bispectral
Infra-Red Detector) Hot Spot Recognition Sensor (HSRS; Zhukov et al., 2006). Freeborn et al. (2014c) also showed that the scatter reduced as fire clusters containing increasing numbers of active fire pixels were compared, since the sub-pixel location effects would increasingly cancel out as more pixels were included in the instantaneous scan-to-scan FRP intercomparison. Nevertheless, given the degree of scatter found between even almost totally simultaneous MODIS FRP observations of the same fire made at the same scan angle and pixel area by Freeborn et al. (2014c), it is unsurprising that higher levels of scatter arises when comparing FRP data from different sensors (Fig. 2; Table 1), where pixel areas, scan angles and imaging time differences are all somewhat greater. Our results indicate that when the FRP-PIXEL product and the MODIS active fire products both detect the same fire, the FRP reported by the two products show small biases. Over the four LSA SAF regions, 391 individual active fire "clusters" detected by MODIS and SEVIRI were compared and $76 \%$ (298 fire clusters) had an FRP within 30\% of that measured by MODIS. Given the uncertainties on perfire FRP retrievals, the LSA SAF target accuracy of the FRPPIXEL product is specified as, on a per-fire basis, $70 \%$ of the SEVIRI-retrieved FRP values being within $50 \%$ of those simultaneously measured by MODIS. Therefore, the FRPPIXEL product significantly exceeds this specification, and actually approaches that specified by the LSA SAF "optimal accuracy" definition (70\% of retrieved SEVIRI-retrieved FRP value being within $20 \%$ of the MODIS-derived value on a per-fire basis).

Whilst our per-fire FRP intercomparison has indicated a comparatively low degree of FRP bias between the FRPPIXEL and MODIS MOD14/MYD14 FRP records of the same successfully detected active fires, there remains a significant degree of regional-scale FRP underestimation by the FRP-PIXEL product due to the inability of the coarser SEVIRI observations to detect the lowest FRP component of a region's fire regime (Roberts and Wooster, 2008). Therefore, when data from both the MOD14/MYD14 and nearsimultaneous matching FRP-PIXEL products covering the same area (i.e. the area covered by MODIS within a $\pm 30^{\circ}$ scan angle) are compared, SEVIRI reports a lower cumulative "regional" FRP than does MODIS (Table 1, column 6). This effect is directly related to SEVIRI's aforementioned active fire errors of omission, an effect that is magnified in geographic regions in which SEVIRI mostly observes at higher view zenith angles. Figure 3 again uses the example of the Northern Africa region, where the slope of the linear of best fit to the regional FRP totals recorded near simultaneously in the FRP-PIXEL product and the MODIS active fire products is 0.65 . This indicates the relatively small, but certainly not insignificant, impact of the FRP-PIXEL product's active fire errors of omission in this region, which is that closest to the Meteosat sub-satellite point (SSP) and thus in which the FRP-PIXEL product's active fire errors of omission are lowest (Table 1). Regional FRP underestimation increases away 


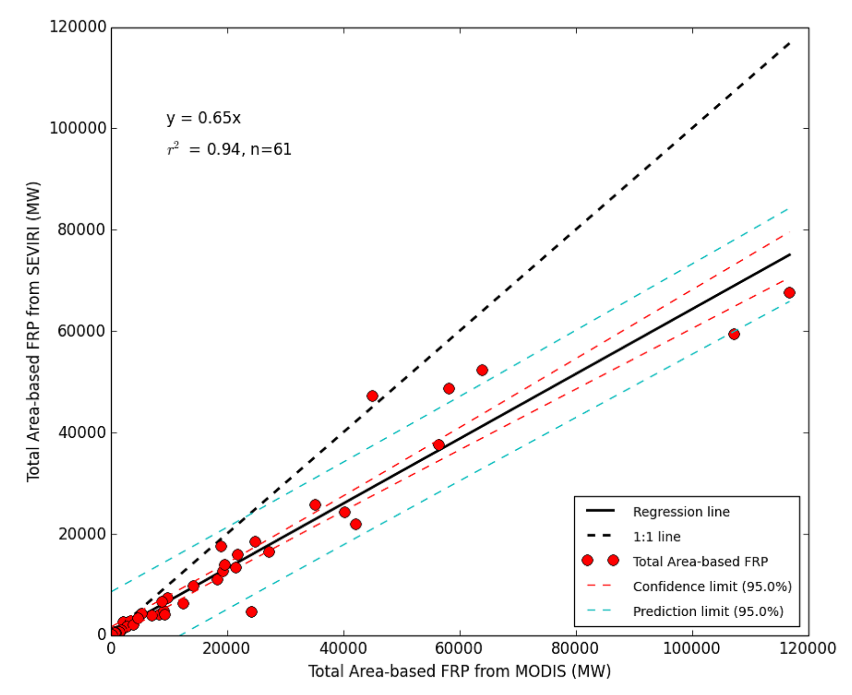

Figure 3. Relationship between regional-scale interscene FRP derived from all spatially matched, contemporaneous SEVIRI and MODIS FRP-PIXEL observations for the Northern Africa region (1-7 December 2009). The MODIS swath is taken as the observation area. The least squares linear best fit passing through the origin is shown (bold line), along with the $95 \%$ confidence intervals on the mean (light dotted line) and on the prediction of $y$ from $x$ (outermost lines). The $1: 1$ line is also shown (dashed). SEVIRI tends to generally underestimate regional-scale FRP, primarily due to the non-detection of the lowest FRP fire pixels, many of which MODIS can detect. However, the degree of underestimation is relatively small as described by the slope of the linear best fit to the data.

from the SSP and appears particularly extreme in the European LSA SAF geographic region in our intercomparison. This is in part a result of a large proportion of active fires being present in eastern Europe during our intercomparison period, where the SEVIRI view zenith angle exceeds $60^{\circ}$. With respect to regional FRP characterisation, the performance of the FRP-PIXEL product for southern European fires, which lie relatively close to the Meteosat SSP, is likely to be much closer to that of the Northern Africa geographic region. Section 5 includes a study of the August 2007 Greek fires as a case study example of fires in this region.

\subsection{Intercomparison of alternative SEVIRI active fire products}

Since the launch of Meteosat Second Generation in 2002, a number of studies have used different algorithms to study active fires with SEVIRI observations (e.g. Calle et al., 2009; Amraoui et al., 2010). This has led to certain other routinely generated SEVIRI active fire products being available, in addition to the LSA SAF FRP-PIXEL product focused upon herein. These alternative SEVIRI-based products include the Wildfire Automated Biomass Burning Algorithm (WFABBA, version 6.5) product (based on the WFABBA fire detection algorithm of Prins et al., 1998), the Fire Detection and Monitoring (FDeM) product (Amraoui et al., 2010), and the Active Fire Monitoring (FIR) product (Joro et al., 2008), each of which essentially generate active fire pixel detections from SEVIRI level 1.5 data as does the FTA algorithm used within the FRP-PIXEL product processing chain (Wooster et al., 2015).

\subsubsection{Methodology}

We assessed the active fire detection performance of the FRP-PIXEL product in comparison to the three main alternative SEVIRI active fire products and to the MODIS MOD14/MYD14 active fire products using the SEVIRI-toMODIS intercomparison methodology detailed in Sect. 3.1. The intercomparison was conducted using all available FRPPIXEL products collected over the Southern Africa LSA SAF geographic region in August 2014 (a total of 2959), a month when fires are highly prevalent in Southern Africa. For comparison we collected all the available files from the alternative SEVIRI active fire data products, a total of 2949 for WFABBA (Prins et al., 1998), 2963 for FDeM product (Amraoui et al., 2010) and 2914 for FIR (Joro et al., 2008). Due to various data collection and processing issues, not all products were available for all SEVIRI source scenes, as is evident from the slightly different (max $1.5 \%$ ) number of products in each case. Also, each product has different classes of output, and the FIR product for example classifies fire pixels as either active fires or potential active fires. In this comparison we focus on only confirmed active fire detections. Similarly, the WFABBA product "filters" active fire pixels detected only once in a $24 \mathrm{~h}$ period and classes them less likely to be fires, aiming to reduce the number of false alarms detected and minimise effects due to sunglint. In our analysis of the WFABBA active fire product we therefore include four variations of the WFABBA data set. These are the inclusion of all fire detections, all the WFABBA-"filtered" detections (where pixels only detected once during $24 \mathrm{~h}$ are removed) and the WFABBA-"filtered" detections keeping only (1) the high probability fires (WFABBA flags 0-3) and (2) high and medium probability fires (WFABBA flags 0-4).

For comparison to the SEVIRI-derived active fire products we used 544 Collection 5 MODIS MOD14/MYD14 active fire products, acquired over Southern Hemisphere Africa. To facilitate comparison with the SEVIRI products, we subset the SEVIRI products to cover the same area as the MODIS products and selected the set of temporally coincident MODIS active fire pixels that matched with SEVIRI active fire products in time $( \pm 6 \mathrm{~min})$. The MODIS active fire pixels were remapped to SEVIRI's imaging grid and had their FRP atmospherically corrected using the same approach as detailed in Sect. 3.1 to match the methodology used to generate the FRP values within the FRP-PIXEL product. SEVIRI's per-pixel point spread function (PSF) at the subsatellite point extends more than $5 \mathrm{~km}$ radially from the pixel 
Table 2. Summary of active fire pixel detection errors of omission and commission for the four SEVIRI-derived active fire products explored herein (LSA SAF FRP-PIXEL product; Wooster et al., 2015, WF-ABBA; Prins et al., 1998, FDeM; Amraoui et al., 2010, and FIR; Joro et al., 2008). Data were collected over the LSA SAF Southern Africa geographic region during August 2014, when fire activity is widespread in this area. The MODIS active fire products (MOD14 and MYD14; Giglio et al., 2003) acted as the independent data source for the comparison.

\begin{tabular}{|c|c|c|c|c|c|c|c|}
\hline & FRP-PIXEL & WFABBA & WFABBA & WFABBA & WFABBA & FDeM & FIR \\
\hline & & All detections & Filtered & $\begin{array}{c}\text { Filtered } \\
(\text { Flags } 0-4)\end{array}$ & $\begin{array}{c}\text { Filtered } \\
\text { (Flags 0-3) }\end{array}$ & & \\
\hline $\begin{array}{l}\text { Number of SEVIRI fire pix- } \\
\text { els at coincident MODIS } \\
\text { overpasses }\end{array}$ & 33414 & 15610 & 13008 & 9736 & 8832 & 7664 & 7151 \\
\hline $\begin{array}{l}\text { Number of SEVIRI fire pix- } \\
\text { els detected by MODIS }\end{array}$ & 29037 & 14521 & 12284 & 9369 & 8496 & 7260 & 6730 \\
\hline Commission error $(\%)$ & 13 & 7 & 6 & 4 & 4 & 5 & 6 \\
\hline Omission error $(\%)$ & 77 & 82 & 84 & 87 & 88 & 92 & 95 \\
\hline
\end{tabular}

centre (Wooster et al., 2015), so following the approach of Freeborn et al. (2014b) we evaluated the SEVIRI-derived active fire detection performances against the presence of MODIS active fire pixels within a $3 \times 3$ pixel window centred on the SEVIRI active fire pixel under investigation. Again, as with Sect. 3.1 the comparison was restricted to MODIS active fire detections made within a $\pm 30^{\circ}$ scan angle (Freeborn et al., 2014b).

\subsubsection{Results}

The MOD14/MYD14 products contained 286000 active fire detections during August 2014 over the Southern Africa LSA SAF geographic region, and once remapped onto the SEVIRI imaging grid, this equated to 112576 pixels. Within the specified \pm 6 min MODIS-to-SEVIRI imaging time limit, the FRP-PIXEL product detects 33414 active fire pixels and 29037 of these are also detected by the remapped MOD14/MYD14 data. This corresponds to a SEVIRI active fire pixel detection commission error of $13 \%$. Using the same SEVIRI level 1.5 data, the WFABBA, FDeM and FIR active fire products detect 13008,7664 and 7151 active fire pixels respectively and, of these, 12284, 7260 and 6730 are coincident with a MODIS active fire detection respectively. Hence, the active fire pixel errors of commission are 5.5, 5.2 and $5.8 \%$ respectively for these three SEVIRI-derived products, active fire errors of commission rates around half those of the FRP-PIXEL product. The WFABBA-filtered data set also stratifies active fire detections according to their detection confidence. We analysed the fire detection performance of the WFABBA-filtered data set by just including medium and high probability fires (flags $0-4$ ) and only high probability fires (flags 0-3). These filtered WFABBA data sets detect 9736 (flags 0-4) and 8832 (flags $0-3$ ) active fires of which 9369 and 8496 are coincident with MODIS active fire pixels. This equates to a reduced commission rate of $4 \%$ for both whilst the omission rate increases to 87 and $88 \%$ respectively.
A summary of the SEVIRI active fire product intercomparison results is given in Table 2 . The $\sim 13 \%$ active fire error of commission rate for the FRP-PIXEL product found here and by Freeborn et al. (2014b) is higher than the $\sim 8 \%$ found by Roberts and Wooster $(2008,2014)$ using the FTA algorithm prototype. The disparity is in part due to the differing way in which the operational FTA algorithm applies a high-pass spatial filter to screen out certain false alarms from the potential fire pixel set (Roberts and Wooster, 2008). As discussed in the companion paper that describes the fire thermal anomaly (FTA) algorithm in detail (Wooster et al., 2015), the current LSA SAF implementation of the FTA algorithm (whose performance results are reported in Table 2) has some characteristics that are open to being updated, namely whether dynamic or static thresholds are used in the spatial filter applied at the end of the potential fire pixel (PFP) stage, and whether application of the cloud-edge mask is really necessary (see Wooster et al., 2015 for details). We have tested these adaptations using 1 month of data (July 2015) collected over the same Southern Africa region used to perform the evaluation reported in Table 2 and have compared the results to those from contemporaneous MODIS overpasses. Results show that with both adaptations applied, the error of commission of the adjusted FTA algorithm compared to MODIS reduce from the current 14 to $12 \%$, whilst the error of omission remains at $70 \%$. These two adaptations are therefore now being implemented in the operational FTA processing chain.

The minimum FRP detection limit of an active fire detection algorithm is directly proportional to the pixel area (Roberts and Wooster, 2008; Wooster et al., 2015). If the active fire detection algorithm of Giglio et al. (2003) used to generate the Collection 5 MOD14/MYD14 MODIS active fire products were applied to SEVIRI level 1.5 imagery, the minimum FRP detection limit at the Meteosat SSP would be $70-80 \mathrm{MW}$, around $10 \times$ the minimum FRP detection limit of the MOD14/MYD14 active fire products due to SEVIRI's 

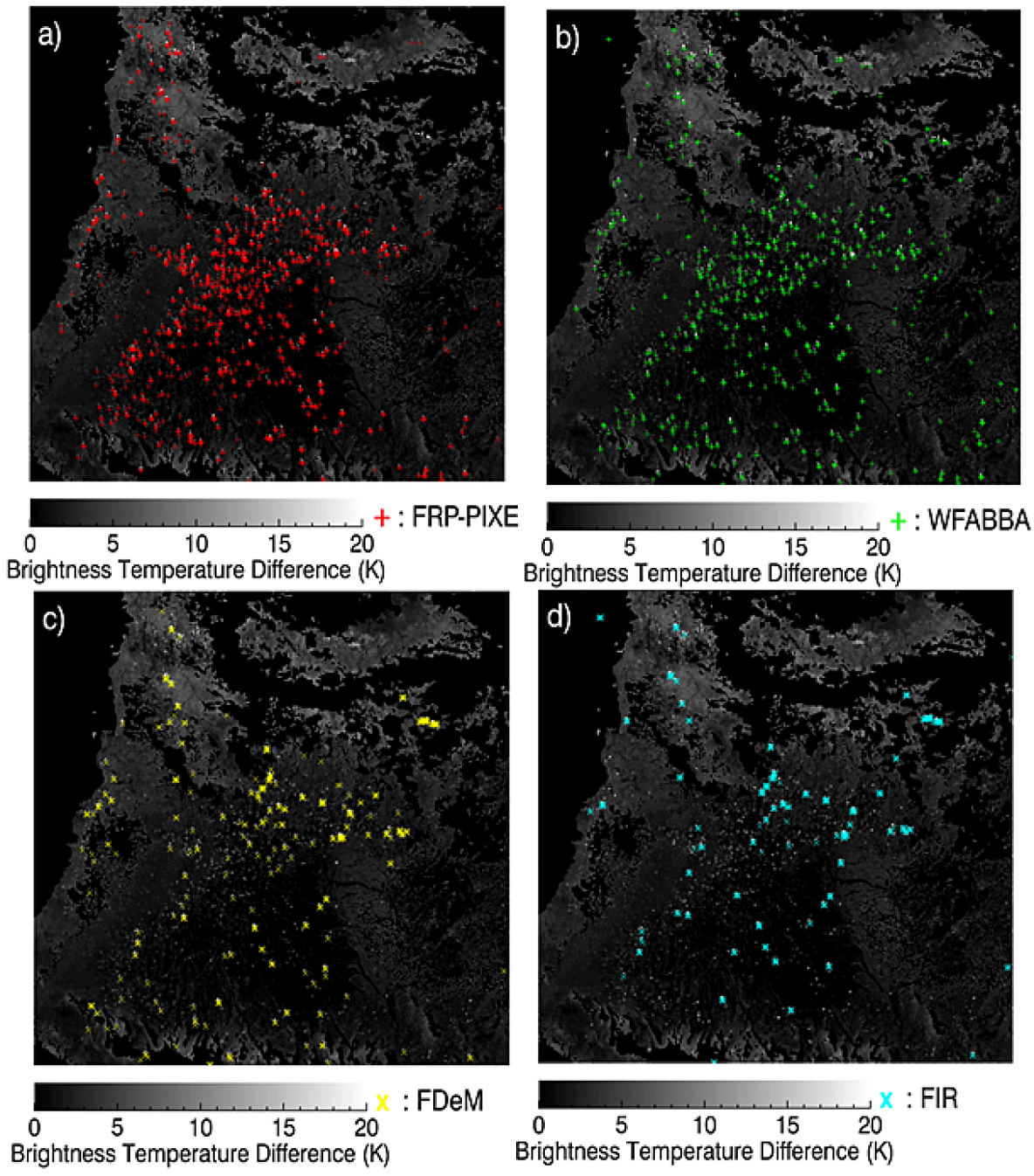

Brightness Temperature Difference $(K)$

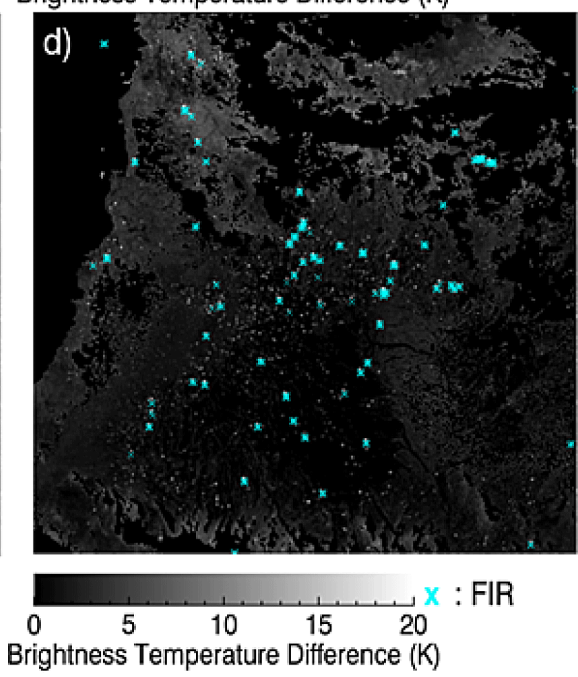

Figure 4. Example of the active fire pixel detections contained within the four SEVIRI-derived active fire detection products studied herein (LSA SAF FRP-PIXEL product; Wooster et al., 2015, WF-ABBA; Prins et al., 1998, FDeM; Amraoui et al., 2010, and FIR; Joro et al., 2008). The images are produced from a single SEVIRI time slot (13:15 UTC on 21 August 2014) and show the active fire detections made in (a) FRP-PIXEL (1249 active fire pixel detections), (b) WFABBA (filtered version; 686 detections made), (c) FDeM (346 detections) and (d) FIR (312 detections). The underlying greyscale image is the SEVIRI brightness temperature difference image (3.9-10.8 $\mu \mathrm{m}$ channels) from the same imaging slot. Water bodies and clouds have been masked out (black). The region shown is that over Angola in the Southern Africa LSA SAF geographic region (Fig. 1). It is clear than whilst all the products tend to detect a reasonable number of fires that are comprised on multiple SEVIRI active fire pixels, it is the FRP-PIXEL and WF-ABBA products that detect more of the single pixel fires, with the FRP-PIXEL product dominating in this regard.

$\sim 10 \times$ larger nadir view pixel area. By contrast, the design of the FRP-PIXEL product attempts to lower the minimum FRP detection limit significantly below this by detecting active fire pixels whose radiometric signals in the MWIR, LWIR and MWIR-LWIR are raised even quite minimally above that of the ambient background (Roberts and Wooster, 2008). By exploiting a variety of spectral and spatial thresholds and contextual processing methods, the FTA algorithm is sometimes capable of detecting SEVIRI active fire pixels having an FRP down to $\sim 20 \mathrm{MW}$ at the Meteosat SSP. Nevertheless, statistics show that for active fire pixels below $\sim 50 \mathrm{MW}$ the active fire pixel count is underestimated more by SEVIRI compared to the performance above this threshold (Freeborn et al., 2009). However, by restricting our comparison of the FRP-PIXEL product to active fire pixels having FRP $\geq 50 \mathrm{MW}$ the active fire pixel error of commission of the FRP-PIXEL product fell only slightly to $12 \%$, indicating that false alarms are not necessarily dominated by these low FRP fire pixels.

Whilst our analysis has shown somewhat higher active fire errors of commission for the FRP-PIXEL product compared to the WFABBA, FIR and FDeM products, we find the 


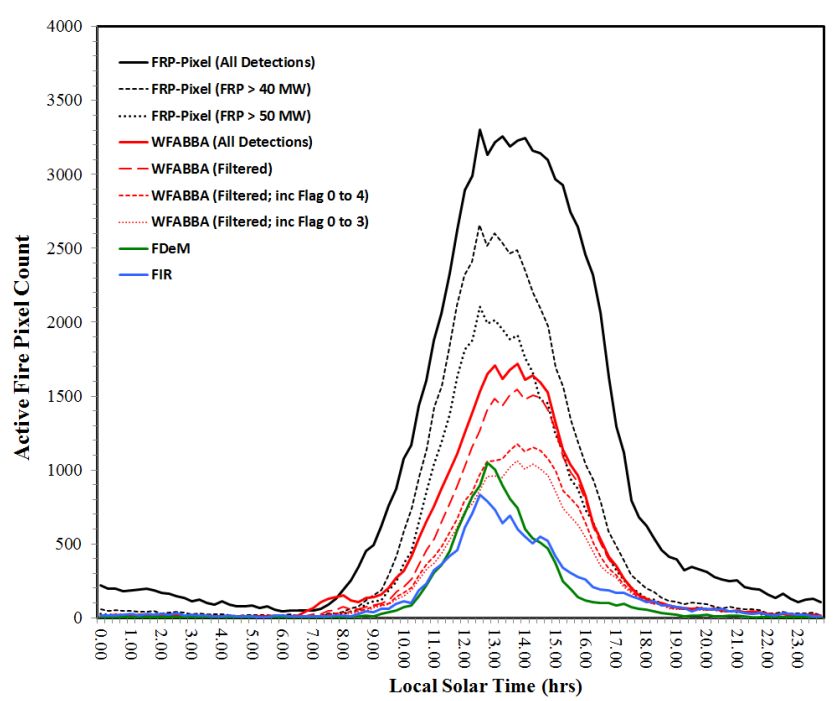

Figure 5. Diurnal cycle of active fire detections present within the four SEVIRI-derived active fire products discussed herein for the LSA SAF Southern Africa geographic region (Fig. 1) on a single day (30 August 2014). The products are the LSA SAF FRP-PIXEL product (Wooster et al., 2015), Wildfire-ABBA (WFABBA; Prins et al., 1998), FDeM (Amraoui et al., 2010) and FIR (Joro et al., 2008). All confirmed active fire detections made in each product are included here for completeness, and results are shown in terms of the local solar time of detection. For the FRP-PIXEL product, three active fire time series are shown: (1) all detections, and only those detections from fire pixels with FRP magnitudes (2) > 40 MW and (3) $>50 \mathrm{MW}$ since it is known that increasing undercounting of active fire pixels occurs around these limits (Roberts and Wooster, 2008; and companion paper in this issue). For the WFABBA active fire detections, all four versions of the data set are included: (1) all active fire detections, (2) the WFABBA-"filtered" detections where active fire pixels only detected once during $24 \mathrm{~h}$ are removed, and the WFABBA-filtered detections keeping only (3) the high probability fires (flags 0-3) and (4) high and medium probability fires (flags 0-4). The LSA SAF FRP-PIXEL product detects a total of 89781 active fire pixels over this day, which reduces to 53561 and 39461 when restricted to fire pixels with FRP $>40 \mathrm{MW}$ and $>50 \mathrm{MW}$ respectively. For WFABBA, the total number of active fire detections is 35759 , and the filtered data set contains 35759 detections which reduces to 30751 and 23957 when WFABBA low and medium probability fire detections are removed. The FDeM and FIR detect only 13477 and 14645 active fire pixels respectively.

latter have much higher active fire errors of omission. Figure 4 illustrates the variation seen in active fire pixel detection performance between the different SEVIRI products for one imaging slot (21 August 2014, 13:15 UTC). In this example, the FRP-PIXEL, WFABBA, FDeM and FIR products detect 1249, 686, 346 and 312 active fire pixels respectively, illustrating a substantial degree of difference. Furthermore, the fire diurnal cycle retrieved using the four products from a single day of data shown in Fig. 5 highlights the fact that these differences are maintained over the course of the day, leading to very large variations in the total count of active fires detected on a daily basis.

When compared to the matching MODIS active fire pixel detections, the WFABBA, FDeM and FIR products contain active fire pixel detections that match 16,8 and $5 \%$ respectively of the MODIS active fire pixels, whereas the figure for the LSA SAF FRP-PIXEL product is substantially higher at $23 \%$. Georgiev and Stoyanova (2013) previously undertook a limited study of the FRP-PIXEL product performance in south-eastern Europe and determined that it provided a marginally higher active fire detection efficiency than did the FIR product. Using a wider area of a region with many more fires covering a wide FRP range we find much larger difference, and indeed the FIR product appears to provide the worst performance of all the four SEVIRI products in terms of its ability to detect active fire pixels. Restricting the FRPPIXEL active fire detections to those pixels $\geq 50 \mathrm{MW}$, the FRP-PIXEL product still detects 9896, 14864 and 15896 more active fire pixels that are coincident with MODIS than do the WFABBA, FDeM and FIR products respectively. This corresponds to active fire pixel count differences in excess of $\sim 175 \%$, even when limiting the detection regime to an FRP range where all the SEVIRI-derived products should in theory be able to show a reasonably strong performance.

Our analysis of the operational FTA algorithm's performance has shown an active fire pixel error of omission rate of $77 \%$ when comparing the FRP-PIXEL product to simultaneously collected MODIS active fire pixels. This omission error is similar to that previously found by Roberts and Wooster (2014) and Freeborn et al. (2014b) for the FTA algorithm, and primarily results from the $\sim 10 \times$ larger nadir pixel area of SEVIRI than MODIS. In comparison, the errors of omission for the WFABBA, FDeM and FIR products are significantly greater, at 84,92 and $95 \%$ respectively. Restricting the comparison to those FRP-PIXEL product pixels having a SEVIRI-retrieved FRP $\geq 50 \mathrm{MW}$, which SEVIRI-based algorithms should be able to detect quite readily, reduces the FRP-PIXEL product active fire pixel error of omission to $\sim 50 \%$ in comparison to MODIS.

In terms of FRP measurements, the ratio between the total cumulative FRP measured within the same Southern Africa geographic region covered by the near-simultaneous FRPPIXEL and MODIS active fire products is 0.48 . This represents a lower underestimate of FRP than might be expected from the FRP-PIXEL omission error rate, and the reason is that the unidentified active fire pixels are predominantly those having low FRP values ( $\ll 50 \mathrm{MW})$. Restricting the analysis to only those active fires that are correctly identified by both products provides a cumulative FRP ratio of 0.96 , showing an excellent agreement in the regional FRP assessment when only active fires successfully detected by both sensors are taken into account. This agrees with the strongperformance in terms of per-pixel FRP assessment seen in Sect. 3.1. 

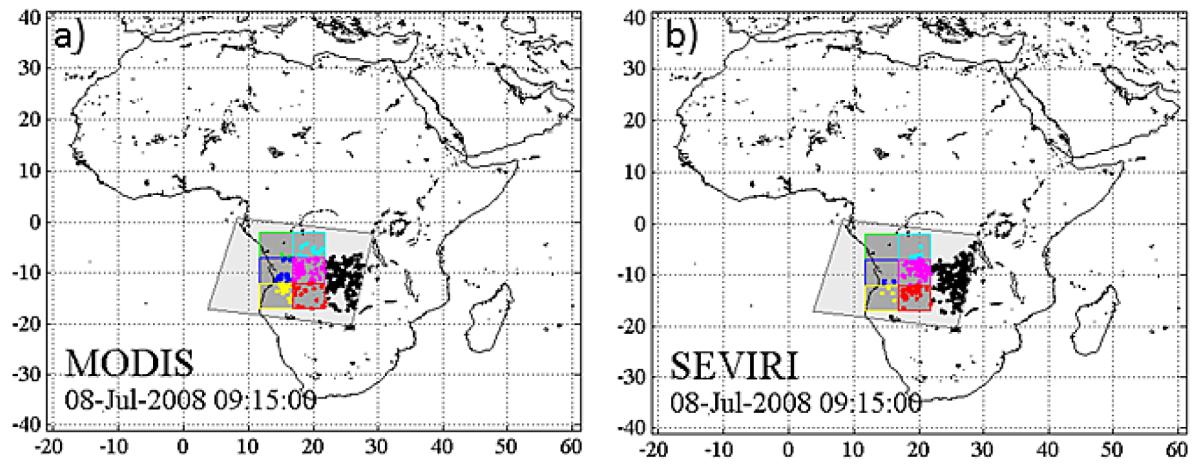

Figure 6. Graphical representation of the procedure used to generate the data set for use in evaluating the bias adjustment factors used within the FRP-GRID product. Fire pixels were subset from the MOD14 and MYD14 MODIS active fire products available between May 2008 and April 2009 using six $5.0^{\circ}$ grid cells centred on the MODIS swath, as illustrated in (a). These same grid cells were then used in (b) to subset fire pixels from the SEVIRI full Earth disk images acquired at times coincident with the MODIS overpass, as well as from the three previous SEVIRI imaging time slots collected prior to the MODIS overpass.

Certain previous studies evaluating the FTA algorithm or prototype FRP-PIXEL data sets (e.g. Roberts and Wooster, 2008; Xu et al., 2010; Roberts and Wooster, 2014) have applied an alternative approach when comparing these to MODIS active fire data sets. Rather than the per-pixel approach to intercomparison applied above, Freeborn et al. (2014a) grouped active fire pixels into contiguous clusters based on their spatial closeness to other active fire pixels in the same manner as that described in Sect. 3.1 for the perfire FRP intercomparison. To strengthen the link between this work and these previous findings, active fire pixels within each of the active fire products tested were also clustered into spatially contiguous groupings, and the active fire detection errors of commission and omission were calculated based on a "fire cluster" basis instead of for the individual fire pixels. We used a similar strategy for this intercomparison as that used at the pixel scale, specifically searching the surrounding $3 \times 3$ pixels for matching active fires in the products to be compared. Using this "clustering" approach, we found the error rates of the FRP-PIXEL product to be higher than those determined using the per-pixel approach, with errors of commission and omission of 19 and $85 \%$ respectively when compared to the matching MOD14/MYD14 products. Again, if only those fire clusters having an FRP $\geq 50 \mathrm{MW}$ are included, these reduce to 18 and $57 \%$ respectively, demonstrating in particular a high success of active fire detection in this region of the FRP regime. Using the same approach with the alternative SEVIRI active fire products, we find that the WFABBA products also show slightly higher errors of omission and commission than when examined at the fire cluster scale, now being $7 \%$ (commission) and $90 \%$ (omission) respectively in comparison to the MODIS product. The error rates for FDeM and FIR products are, however, very similar when examined on a fire cluster basis to the results on a per fire pixel basis, with a commission rate of $6 \%$ for both and an omission rate of 96 and $95 \%$ for FDeM and FIR respectively.

\section{FRP-GRIDDED product evaluation}

\subsection{Method}

Section 2.2 detailed how the LSA SAF SEVIRI FRP-GRID product uses a series of regionally specific bias adjustment factors $(\alpha)$ to upwardly adjust regional FRP estimates for e.g. the impact of undetected low FRP fire pixels. The aim is to produce an hourly, regional FRP estimate that has minimal bias compared to if MODIS had been able to view the same area at the same time. Full details of the FRP-GRID processing chain are included in Wooster et al. (2015). We evaluated the performance of the applied bias adjustments using a validation data set composed of coincident SEVIRI and MODIS observations collected between May 2008 and May 2009 in each of the four LSA SAF geographic regions. Boundaries of the relevant MODIS level 2 swath products were used to identify all MODIS granules that intersected each region during the year-long study period and fire pixels subset from the full MODIS MOD14 and MYD14 products using six, non-overlapping $5.0^{\circ}$ grid cells arranged in the centre of each MODIS granule (Fig. 6). Active fire pixels detected by MODIS outside of this region of interest were discarded and not used during the analysis. The sampling design ensured complete coverage of the $5.0^{\circ}$ grid cells regardless of the MODIS ground track and also mitigated the effects of image distortion at the edge of the MODIS swath. All MODIS granules collected during the year-long study period were matched to the most concurrent SEVIRI image, always within $\pm 6 \mathrm{~min}$ of each other. The same $5.0^{\circ}$ grid cells inscribed within the MODIS granule were then used to clip SEVIRI fire pixels from both (i) the most coincident SEVIRI time slot and (ii) the three SEVIRI time slots immediately preceding the MODIS overpass. Again, active fire pixels detected by SEVIRI outside of this region of interest were not included in the analysis. Entire grid cells were also discarded 

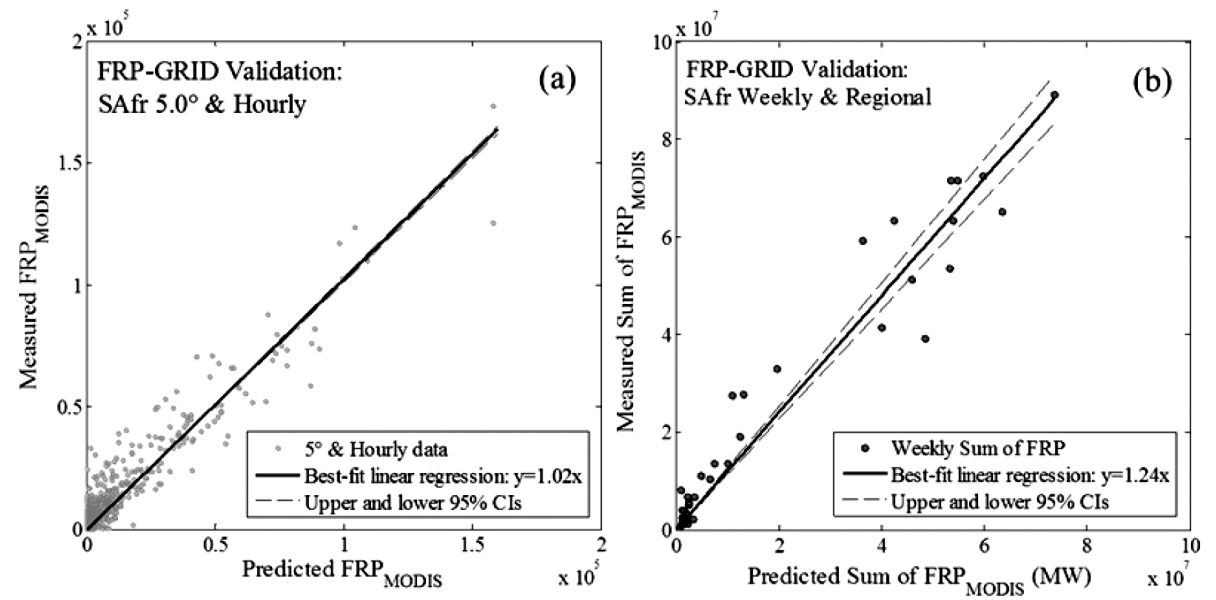

Figure 7. Evaluation of the bias adjustment factors used in the SEVIRI FRP-GRID product. Results are based on coincident SEVIRI and MODIS observations taken between May 2008 and May 2009, collected and matched as shown in Fig. 6. The nearly $1: 1$ relationship between the predicted and measured values of MODIS FRP demonstrates the unbiased nature of the adjustment factor applied at (a) $5.0^{\circ}$ grid cell resolution and hourly temporal resolution in the FRP-GRID product, in this case for $5.0^{\circ}$ grid cells in Southern Africa. In (b) the effect of accumulating observations over weekly intervals and over the entire Southern Africa LSA SAF geographic region demonstrates that the FRP-GRID product tends to still deliver a result that underestimates the sum of FRP measured by MODIS at this broader spatio-temporal scale, owing primarily to the numerous observations in which SEVIRI failed to detect at least one active fire pixel in a $5.0^{\circ}$ grid cell in which MODIS did successfully detect a fire. Full results of the evaluation exercise for all four geographic regions are presented in Table 3.

if three consecutive SEVIRI imaging time slots could not be retrieved prior to the SEVIRI time slot concurrent with the MODIS overpass (i.e. if four imaging time slots were not available). This sampling design not only permitted a genuine comparison of coincident SEVIRI and MODIS observations of FRP but also mimicked the hourly temporal resolution of the gridded FRP product.

After the SEVIRI and MODIS fire pixels were spatially and temporally accumulated, half of the concurrent and collocated $5.0^{\circ}$ grid cells in each region were used to generate the validation data set. Relationships between the atmospherically corrected FRP observed by SEVIRI and MODIS were directly compared among the $5.0^{\circ}$ grid cells contained within this data set. Rather than using the instantaneous FRP observed by SEVIRI at the time slot most concurrent with the MODIS overpass however, the mean FRP generated from the SEVIRI data available over the preceding hour was used instead to correspond more appropriately with the hourly resolution of the FRP-GRID product.

\subsection{Results}

A complete summary of the FRP-GRID product validation results derived from the methodology detailed in Sect. 3.1 is provided in Table 3. Application of the weighted least squares (WLS) coefficients in Northern and Southern Africa to the validation data set yielded unbiased estimates of the instantaneous FRP that would have been measured by MODIS at $5.0^{\circ}$ spatial resolution (e.g. Fig. 7a, Table 3). As expected, however, the region-specific coefficients for the South America (SAme) and Europe (Euro) geographic regions did not perform as well. Although the adjustment procedure provides an unbiased estimate of the FRP that MODIS would have measured in South America, the coefficient of determination $\left(r^{2}\right)$ indicates that confidence in the predictive capability of the model is limited at this spatial and temporal resolution. As a caveat, however, the validation results in South America and Europe are influenced by observations when SEVIRI did not detect a single active fire pixel within a $5.0^{\circ}$ grid cell during the hour. After removing $5.0^{\circ}$ grid cells that only contained an active fire pixel detected by a single sensor (i.e. thereby forcing a comparison between observations in which both SEVIRI and MODIS viewed a fire) the $r^{2}$ improved to 0.43 in the South America region. Furthermore, removing a lone outlier improved the correlation coefficient slightly further to 0.55. Likewise for Europe, only including observations in which SEVIRI and MODIS simultaneously detected an active fire pixel yielded an $r^{2}$ of 0.31 .

Of course, the linear bias adjustments applied in the FRPGRID product only capture the underlying macroscopic features of the sensor-to-sensor relationships and do not account for any temporal variability in the SEVIRI-to-MODIS ratios of FRP induced by diurnal or seasonal fluctuations in fire activity (e.g. as seen in Freeborn et al., 2009). By deriving different regression coefficients for each of the four LSA SAF regions, however, the FRP-GRID algorithm does account for broad spatial differences in the sensor-to-sensor relationships that potentially arise from (i) differences in fire regimes and (ii) differences in SEVIRI view zenith angles.

To assess the predictive capability of the bias adjustment factors at broader spatial and temporal scales than simply the 
Table 3. Summary of the results related to evaluation of the regional bias adjustment factors implemented during the processing of the LSA SAF FRP-GRID product. Slope of the linear best fit between the SEVIRI-predicted regional FRP using the FRP-GRID bias adjustment factors and the FRP measured by MODIS over the same areas are shown, as are the coefficients of determination $\left(r^{2}\right)$, at both $5^{\circ}$ and hourly resolution (which is the native FRP-GRID product resolution) and also at a weekly resolution accumulated over the entire LSA SAF geographic region.

\begin{tabular}{llcc}
\hline LSA SAF Region & Abbreviation & \multicolumn{2}{c}{ Validation results: slope $\left(r^{2}\right)$} \\
\cline { 3 - 4 } & & $5.0^{\circ}$ and hourly & weekly and regional \\
\hline Northern Africa & NAfr & $1.04(0.76)$ & $1.15(0.96)$ \\
Southern Africa & SAfr & $1.02(0.91)$ & $1.24(0.97)$ \\
South America & SAme & $0.97(0.34)$ & $1.89(0.83)$ \\
Europe & Euro & $1.72(0.19)$ & $4.94(0.84)$ \\
\hline
\end{tabular}

hourly $/ 5^{\circ}$ spatio-temporal resolution of the FRP-GRID product, the SEVIRI and MODIS validation data were accumulated over weekly intervals and comparisons were performed at scale of the LSA SAF geographic regions. Figure 7b illustrates that, in Southern Africa, the bias adjustment factors used to generate the FRP-GRID product consistently underestimate the weekly sum of FRP measured by MODIS across this region and that these results are typical of all four regions (Table 3). Again, this systematic underestimation is partly attributed to the challenge of performing a bias adjustment when SEVIRI does not detect a fire pixel (i.e. the linear bias adjustment coefficient is then applied to an FRP of zero). Nevertheless, the weekly/regional biases shown in Table 3 could in turn be used to adjust the SEVIRI FRPGRID product measurements to deliver unbiased estimates of the FRP that would have been measured by MODIS at the regional/weekly scale.

\section{Example of application of the LSA SAF Meteosat SEVIRI FRP products in the Copernicus Atmosphere Monitoring Service (CAMS)}

\subsection{Introduction to FRP-PIXEL product use in atmospheric transport models}

From the FRP-PIXEL product evaluation and intercomparison conducted in Sect. 3 it is apparent that the FRP-PIXEL product detects a larger proportion of the "true" landscapescale fire activity than do alternative SEVIRI-derived active fire products, albeit with a higher commission rate. That evaluation also highlighted the failure of the FRP-PIXEL product to detect many of the actively burning fires that MODIS would detect, particularly the lower FRP fires, resulting in an overall omission rate of $77 \%$ over the four geographic regions (Table 1). The degree of difference between geostationary and polar-orbiting active fire products does, however, vary with factors such as geographic location, season and time of day (which all influence the type of fire regime and its subcomponents being sampled), sensor viewing geometry, land cover heterogeneity, fire detection algorithm and the quality of ancillary data such as cloud masks (Freeborn et al., 2014b; Schroeder et al., 2008; Roberts and Wooster, 2014; Xu et al., 2010). Indeed, under some conditions, geostationary active fire data sets compare rather favourably against those derived from polar-orbiting sensors. Georgiev and Stoyanova (2013) analysed a series of short-lived wildfires in south-eastern Europe with the FRP-PIXEL product, and found the higher temporal resolution of SEVIRI resulted in a $50 \%$ lower active fire omission rate than did the use of MODIS. Wooster et al. (2015) also demonstrate that, taking the Central African Republic as an example, most fires detected by the MODIS are detected by the SEVIRI FTA algorithm, just not necessarily at the same time as the fire is detected by MODIS. Indeed, the high temporal frequencies offered by geostationary observations can enable the diurnal fire cycle and related short-term changes in fire activity to be far better characterised than with polar-orbiting data, and this ability is starting to be exploited to parameterise wildfire emissions in atmospheric transport models.

One such example is provided by Baldassarre et al. (2015), who used the FRP-PIXEL products (Wooster et al., 2015) and the WFABBA SEVIRI products (Zhang et al., 2012), along with MODIS-derived information from the GFAS inventory of Kaiser et al. (2012), to derive biomass burning emissions inputs for simulations of emissions from a large fire in Turkey (Antalya, 2008). The FRP-PIXEL product provided by far the most accurate description of the emissions, both with regard to their spatio-temporal variation and their absolute magnitude. Unlike the MODISderived GFAS inventory, the SEVIRI FRP-PIXEL product was able to capture the fires' complete life cycles, including the time of peak emissions intensity. And compared to the WFABBA product, the FRP-PIXEL product produced information more consistent with that from MODIS when both SEVIRI and MODIS viewed the Antalya region simultaneously. The simulated smoke plume produced by ingesting the FRP-PIXEL data into the Community Multi-scale Air Quality (CMAQ) atmospheric chemistry model compared far better with observations of MODIS-derived aerosol optical depth (AOD), and with carbon monoxide and ammonia col- 


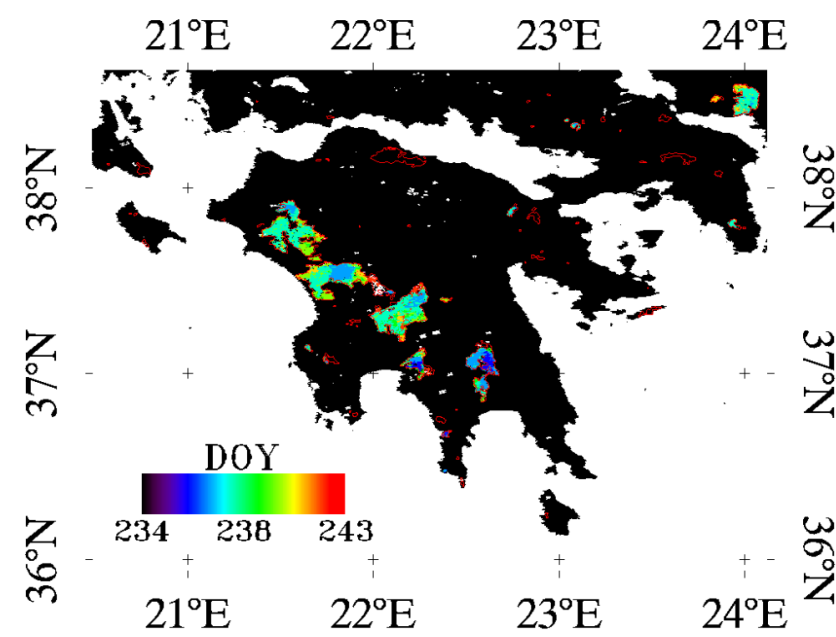

Figure 8. The Peloponnese wildfires as viewed by the MODIS $500 \mathrm{~m}$ burned area of Roy et al. (2005) collected in August and September 2007 and coloured by day of the year they were detected (DOY). The fires occurred in areas of forest, shrublands and olive groves and affected $1847 \mathrm{~km}^{2}$ according to these data. Also shown as a red outline are the 2007 burned area perimeters extracted from the European Forest Fire Information System (EFFIS; European Commission, 2010) that encompass $1628 \mathrm{~km}^{2}$.

umn totals provided by the Infrared Atmospheric Sounding Interferometer (IASI), in particular in relation to the diurnal variability of the fire emissions and the spatial distribution and peak concentrations of the smoke. Please refer to Baldassarre et al. (2015) in this Monitoring Atmospheric Composition and Climate (MACC) special issue for further information on the simulation and intercomparison. Here we provide a second European demonstration of the value of geostationary FRP data in the parameterising of wildfire emissions for use in atmospheric transport models, building on a previous more limited study conducted by Kaiser et al. (2009a).

\subsection{Methodology for modelling emissions and transport of smoke from the 2007 Greek "mega-fire" event}

We use the FRP-PIXEL product as the basis for calculating smoke emissions to the atmosphere from a catastrophic mega-fire event that occurred around the Mediterranean, in particular focused on the Greek island of Peloponnese, in August and September 2007. We use these emissions within components of the CAMS modelling systems to simulate the transport and fate of the emitted smoke, ultimately estimating the level of human exposure to high levels of particulate matter $\left(\mathrm{PM}_{2.5}\right)$. The Peloponnese wildfires occurred after a period of prolonged drought (Gitas et al., 2008), and during a heatwave (Theoharatos et al., 2010). The MODIS burned area product (Roy et al., 2005) indicates they burned across an area of around $1847 \mathrm{~km}^{2}$ (Fig. 8), a figure in good agreement with burned area reports provided by the local
Hellenic fire brigade $\left(1899 \mathrm{~km}^{2}\right)$. The Peloponnese fires predominantly occurred in forested land, both coniferous and broadleaved forest, though some areas of shrublands, grasslands and olive groves were also affected (Veraverbeke et al., 2010; Koutsias et al., 2012). Such was their severity that $0.32 \mathrm{Tg}(40 \%)$ of the estimated mean annual carbon monoxide (CO) emissions for Greece overall were estimated to have been released by these fires alone (Turquety et al., 2009). The fires contributed greatly to reductions in local air quality, with $\mathrm{PM}_{10}$ values in Athens reaching almost $100 \mathrm{~g} \mathrm{~m} \mathrm{~m}^{-3}$, double that of the European Union ambient air quality standard for daily $\mathrm{PM}_{10}\left(50 \mu \mathrm{g} \mathrm{m}^{-3}\right)$. Outside Athens at a background non-urban site, on 24-25 August the $\mathrm{PM}_{10}$ concentration rose to $49 \mathrm{\mu g} \mathrm{m}^{-3}$, significantly up from the

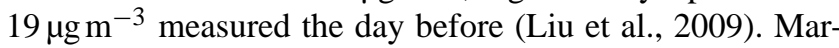
lier et al. (2014) and Reid et al. (2009) have already highlighted the potential improvements that high temporal resolution source information can have on the modelling of biomass burning emissions transport, and the exceptional and strongly varying intensity of the Peloponnese fires provides an excellent opportunity to demonstrate this further using SEVIRI-derived FRP observations.

\subsubsection{Derivation of smoke emissions fields from FRP-PIXEL data}

FRP-PIXEL data of the European LSA SAF geographic region collected between 1 August and 13 September 2007 was examined for signals of the fires that occurred around the Mediterranean during July-August 2007. Clear FRP signals were apparent from these fires, particularly those on Peloponnese, but it was also evident that the adjusted version of the cloud mask (CMa) of Derrien and Le Gleau (2005) delivered by the Nowcasting and Very Short Range Forecasting SAF (NWC SAF; www.nwcsaf.org) and used within the FRP-PIXEL product processing chain (Wooster et al., 2015) was identifying some of the extremely thick smoke emitted by these fires as cloud. This is appropriate for studies requiring clear sky observations, but the sensitivity of the algorithm for detecting cloud- or smoke-contaminated pixels can occasionally result in the omission of fire activity. Since cloud masking is one of the first things conducted within the FRP-PIXEL product processing chain (Wooster et al., 2015), misidentification of very thick smoke as cloud prevents fires being identified in these pixels using the FTA algorithm, even though we know that active fires can be quite reliably detected through even quite thick smoke (Petitcolin and Vermote, 2002). This is because smoke particles have a diameter typically much smaller than the wavelength of the MWIR band and so do not act as strong scatterers of the fire-emitted radiation, unlike meteorological clouds (Kaufman and Remer, 1994). Analysis of the raw SEVIRI level 1.5 data, along with the EUMETSAT Meteorological Product Extraction Facility (MPEF) cloud mask (Tjemkes and Schmetz, 1997), confirmed the identification of some areas of thick smoke as 
cloud by the CMa cloud mask, and also confirmed that the true median percentage cloud cover over Peloponnese was low over the period of the mega-fire event (13\%). To prevent the masking out of smoke-covered fires, which also then impacts surrounding pixels due to the single pixel wide mask that is applied around cloud and water pixels (Wooster et al., 2015), for this particular application we decided to turn off the use of the adjusted CMa cloud mask and simply relied on the basic cloud masking tests used within the FTA algorithm itself (Wooster et al., 2015). Currently investigations are ongoing to make the cloud masking within the FRP-PIXEL product less sensitive to thin cloud and other atmospheric phenomena through which fires can still be identified, including very thick smoke (Wooster et al., 2015).

We then gridded the FRP data from within the FRP-PIXEL product to $0.1^{\circ}$ grid cells and calculated the mean FRP for each cell at an hourly temporal resolution. As with the operational version of the GFAS (Kaiser et al., 2012), the FRP density $\left(\widetilde{\varrho}_{j}, \mathrm{~W} \mathrm{~m}^{-2}\right)$ for each cell was then calculated by normalising the measured FRP by the grid cell area $\left(a_{j}, \mathrm{~m}^{2}\right)$ :

$\widetilde{\varrho}_{j}(d, h)=\frac{1}{a_{j}} \frac{1}{4} \sum_{k=0,15,30,45 i_{k} \in j} \sum_{i k}(d, h)$,

where $d, h$ and $k$ are the date, hour and minute of the SEVIRI observations respectively, and $\sum F_{i k}$ is the summation of all FRP measurements within grid cell $j$.

The rate of dry matter (DM) fuel consumption $(\varphi$, $\mathrm{kg} \mathrm{s}^{-1} \mathrm{~m}^{-2}$ ) was derived from the FRP density measures of each grid cell ( $\left.\varrho, \mathrm{W} \mathrm{m}^{-2}\right)$ following the method described in Wooster et al. (2005):

$\varphi(d, h)=c \times \widetilde{\varrho}(d, h)$,

where $d$ is the day, $h$ is the hour and $c$ is the conversion factor that relates fuel consumption to FRP and which is $0.368 \pm 0.015\left(\mathrm{~kg} \mathrm{MJ}^{-1}\right.$; Wooster et al., 2005). The approach was further developed with land-cover-dependent adjustments by Kaiser et al. (2012). However, we maintain the original fuel consumption estimation and adjust the emission fluxes at the level of the emission factors, see Sect. 5.2.2.

\subsubsection{FRP-derived aerosol emissions and atmospheric modelling}

Ichoku and Kaufmann (2005) first developed an approach to estimate aerosol emissions using FRP and AOD measurements using "coefficients of emission" that related FRP to total particulate matter (TPM) as a function of land cover type. The approach implemented herein calculates emissions using the DM fuel consumption rate $\varphi\left(\mathrm{kg} \mathrm{s}^{-1} \mathrm{~m}^{-2}\right)$ :

$\Phi_{s}(d, h)=\eta_{s} \times \varphi(d, h)$,

where $\Phi_{s}$ is the emission flux density $\left(\mathrm{kg} \mathrm{s}^{-1} \mathrm{~m}^{-2}\right)$ of species $s, d$ is the day, $h$ is the hour and $\eta$ is the emissions factor
Table 4. Trace gas and particulate smoke emission factors $(\eta)$ for species $(s)$ based on extratropical forest fuels, taken from Andreae and Merlet (2001).

\begin{tabular}{ll}
\hline Species & $\begin{array}{l}\text { Emissions factor } \\
\left(\mathrm{g} \mathrm{kg}^{-1} \mathrm{DM}\right)\end{array}$ \\
\hline Black carbon $(\mathrm{BC})$ & $1.7^{*}$ \\
Organic carbon $(\mathrm{OC})$ & $8.6-9.7$ \\
Organic matter $(\mathrm{OM})$ & $42^{*}$ \\
Total particulate matter (TPM) & $17.6 \pm 6.4$ \\
Fine mode aerosol (PM & $2.5)$ \\
Carbon Monoxide (CO) & $13.0 \pm 7.0$ \\
\hline
\end{tabular}

* The emission factor for BC and OC was derived specifically for use in this study (see main text).

$\left(\mathrm{kg} \mathrm{kg}^{-1}\right)$ given by

$\eta_{s}=\alpha(s) \times \kappa_{1}(s)$,

where $\kappa_{1}$ is the land cover (1) specific emissions factor for species $s$ and $\alpha$ is a constant which is used to adjust bottom-up aerosol emissions estimates to those observed in top-down inventories. A regionally varying bias occurs between bottom-up-derived aerosol emissions and MODIS AOD measurements, requiring the former to be adjusted when being used in air quality or climate model simulations (Petrenko et al., 2012). Yang et al. (2011) also found smoke emissions $\left(\mathrm{PM}_{2.5}\right)$ derived using the bottom-up approach were underestimated by a factor of 3 when compared to MODIS AOD retrievals. Kaiser et al. (2012) recommend a global aerosol enhancement by a factor of 3.4 as first-order correction. These values are also broadly consistent with differences of up to a factor of 3 found by Ichoku and Kaufmann (2005) using satellite observations of FRP and AOD compared to measurements of $c \times \kappa_{1}(s)$ derived from laboratory measurements. Here, we estimate emissions of organic matter and black carbon in exact agreement with Ichoku and Kaufmann (2005), by enhancing their emission factors for Andreae and Merlet (2001) with a factor of 3.1. According to the GFEDv3 land cover data set, also used for our calculations in GFAS (Kaiser et al., 2012), the fire-affected region of Greece is classed as extratropical forest and the emitted species and relevant emissions factors are given in Table 4.

The atmospheric aerosol model (Morcrette et al., 2008) used within the ECMWF IFS represents smoke aerosols as black carbon (BC) and organic matter (OM), of both hydrophilic and hydrophobic types. Emissions of the latter are approximated by scaling organic carbon (OC) emissions estimates by a factor of 1.5. Other aerosols included in the modelling are sea salt, dust and sulfate aerosols, and advection, convection, diffusion, dry and wet deposition and chemical conversion of these aerosols are simulated, with meteorology nudged to the operational ECMWF analysis every $12 \mathrm{~h}$. The aerosol abundance, however, is based solely on source and sink processes and the atmospheric transport. In this study 
the IFS model was run with a horizontal resolution of $25 \mathrm{~km}$ (T799) and with 91 vertical levels up to $0.01 \mathrm{hPa}$.

Smoke emissions from the Peloponnese fires were calculated using Eqs. (3) and (4), along with the emissions factors given in Table 4. The smoke emissions must be injected into the atmosphere at a particular height, or distribution of heights, and such injection height assumptions can have implications for the resulting spatio-temporal distribution of the emitted species. Leung et al. (2007) and Guan et al. (2008) demonstrated that use of more detailed plume injection height assumptions resulted in a reduction in nearsurface $\mathrm{CO}$ concentrations, since more plumes were assumed to be lofted above the boundary layer. Paugam et al. (2015b) provided a recent review of approaches to estimate smoke plume injection height, including the methods of Sofiev et al. (2012) and Paugam et al. (2015a) that use FRP measurements to characterise wildfire thermal properties related to plume rise. This research remains at a relatively early stage, but it appears that FRP measures may indeed have a role to play in characterising smoke plume injection height as well as the rate of emission of chemical and aerosol species. Here we retained the commonly used assumption that the calculated smoke emissions are injected into the lowest atmospheric level, since this is generally what has been assumed in the series of MACC projects thus far (Kaiser et al., 2012). The CAMS is anticipated to use injection heights from Paugam et al. (2015a) in the future.

\subsection{Results}

\subsubsection{Fuel consumption during the Peloponnese wildfires}

Figure 9a illustrates the temporal dynamics of total fire FRP (MW) and the equivalent rate of fuel consumption $\left(\mathrm{ts}^{-1}\right)$, calculated from the MODIS and SEVIRI FRP measurements at their native temporal resolutions. The period of greatest fire activity occurs between 23 and 27 August, where the initial active fire detections made by SEVIRI and MODIS occur at 07:57 and 09:00 UTC respectively (23 August). At their most intense, the Peloponnese fires consumed over $15 \mathrm{ts}^{-1}$ of biomass, and such was their intensity that large quantities of fuel $\left(>3 \mathrm{ts}^{-1}\right)$ were consumed even during the night, a period when more landscape typically fires die down quite considerably due to less fire-conducive ambient conditions (Roberts and Wooster, 2007; Roberts et al., 2009). The temporally intermittent MODIS Terra and Aqua FRP measurements broadly capture the pattern seen in the much more frequent SEVIRI data and are typically much higher in magnitude. On the 25 August, MODIS Aqua (12:05 UTC) detects a total FRP exceeding $180 \mathrm{GW}$, with the SEVIRI FRP (12:12 UTC) much lower $(38 \mathrm{GW})$. The large difference mainly derives from the fact that whilst $10 \%$ (31) of the MODIS active fire pixels have an FRP $>1600 \mathrm{MW}$ and $5 \%>3000 \mathrm{MW}, 23 \%$ of the 100 active fire pixels detected a)

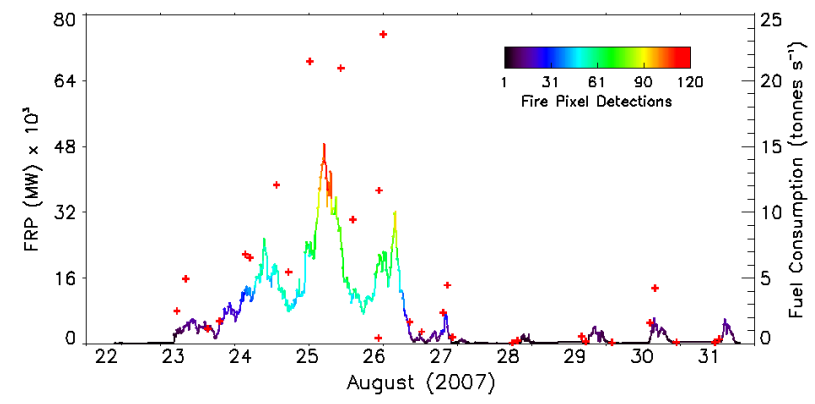

b)

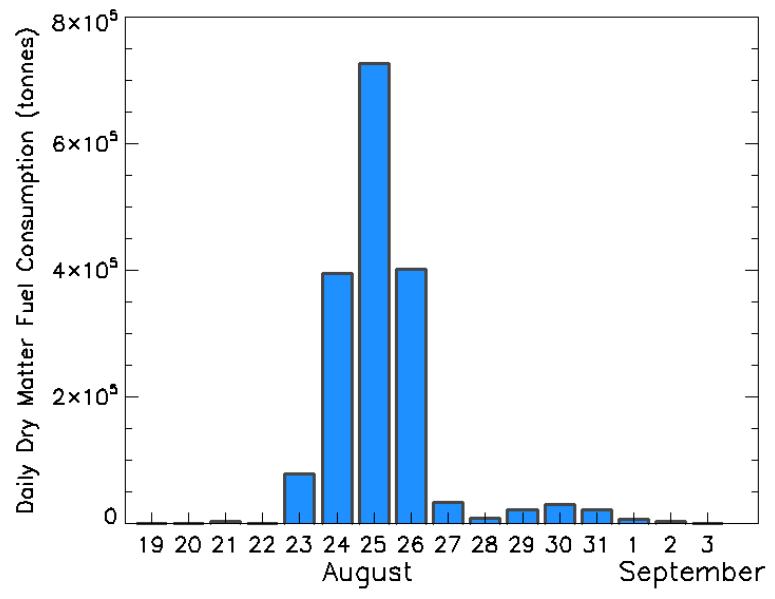

Figure 9. (a) Time series of atmospherically corrected SEVIRI FRP measures (MW, left axis) and equivalent fuel consumption rate $\left(\mathrm{ts}^{-1}\right)$ for the Peloponnese wildfires, as measured between 22 and 31 August 2007 using the LSA SAF SEVIRI FRP-PIXEL product. Also shown are the atmospherically corrected MODIS FRP data collected over the same time period (red crosses). Note that for clarity of presentation the MODIS FRP measure recorded on 25 August (12:05 UTC) is not shown as this exceeds $180 \mathrm{GW}$, and SEVIRI reaches a far lower value due to strong prevalence of SEVIRI MWIR channel pixel saturation at this time. (b) Daily total dry matter fuel consumption estimated using the time-integrated SEVIRI FRP data. We estimate $1.74 \mathrm{Tg}$ of fuel was consumed in these fires, the bulk of which was burned between 24 and 26 August.

by the FRP-PIXEL product are in fact saturated in the SEVIRI MWIR channel. Between 24 and 26 August, when the wildfires were most intense, MODIS made 13 overpasses and the unadjusted SEVIRI observations measured $39 \%$ of the total FRP measured by MODIS. This demonstrates the massive scale and intensity of these fires, particularly given that SEVIRI's pixel area at this location is around $14 \mathrm{~km}^{2}$.

Temporal integration of the SEVIRI FRP measurements between 23 August and 3 September indicates an energy release of $4.73 \mathrm{PJ}$ which, following Eq. (2), equates to $1.74 \mathrm{Tg}$ of combusted fuel, predominantly consumed over 23-27 August (Fig. 9b). Various burned area estimates exist for the Peloponnese fires, including $1773 \mathrm{~km}^{2}$ (Gitas et al., 2008), $1628 \mathrm{~km}^{2}$ (European Forest Fires Information 


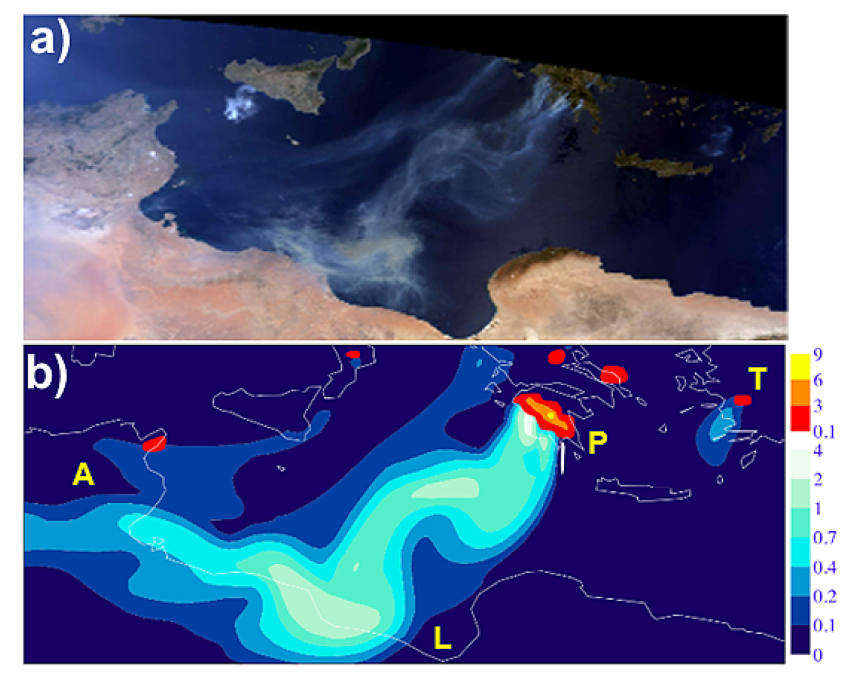

Figure 10. (a) MODIS Terra "true" colour composite derived for 26 August (09:35 UTC) and (b) fire-emitted smoke aerosol optical depth at $550 \mathrm{~nm}$ derived using the modelling scheme detailed in Sect. 5.2 (blue scale) along with SEVIRI-derived FRP-density observations derived from the FRP-PIXEL product $\left(\mathrm{W} \mathrm{m}^{2}\right.$, top, red scale) and interpolated to the atmospheric model grid. The FRPPIXEL observations indicate the smoke plume sources and highlight the strength of the Peloponnese fires at this time. The Peloponnese (P), Libya (L), Algeria (A) and Turkey (T) fires are identified. MODIS data source in (a): http://rapidfire.sci.gsfc.nasa.gov.

System, EFFIS; European Commission, 2010) and $1847 \mathrm{~km}^{2}$ (Roy et al., 2005; Fig. 8). Dividing the SEVIRI FRP-derived fuel consumption with these burned areas provides mean DM fuel consumptions of $0.98,1.07$ and $0.94 \mathrm{~kg} \mathrm{~m}^{-2}$ respectively. Aleppo pine forests occupy around 370000 ha in Greece and are abundant on Peloponnese (Verroios and Georgiadis, 2011). Mitsopoulos and Dimitrakopoulos (2013) assessed 40 stands in this fuel type and found canopy fuel loads to range between 0.63 and $1.82 \mathrm{~kg} \mathrm{~m}^{-2}$, estimating a mean of $1.08 \mathrm{~kg} \mathrm{~m}^{-2}$. Using the maximum fuel load $\left(1.82 \mathrm{~kg} \mathrm{~m}^{-2}\right)$, the three burned area estimates $(1773,1628$ and $1847 \mathrm{~km}^{2}$ ), and assuming a combustion completeness value for forest of 0.6 (van der Werf et al., 2006) we calculated a fuel consumption for these fires of 1.94, 1.77 and $2.01 \mathrm{Tg}$ respectively using the standard burned-area-based approach (Seiler and Crutzen, 1980), which is similar to our SEVIRI-derived estimate of $1.74 \mathrm{Tg}$. Turquety et al. (2009) estimate that $0.32 \mathrm{Tg}$ of $\mathrm{CO}$ was emitted during the Peloponnese fires, which using the emissions factors given in Table 4 results in a larger top-down-derived fuel consumption of $3.0 \mathrm{Tg}$ (with a stated uncertainty of $\sim 30 \%$ ). Due to the aforementioned SEVIRI MWIR channel saturation, the SEVIRI FRP-derived fuel consumption estimate is considered a minimum estimate.

\subsubsection{Smoke plume evolution}

The Peloponnese wildfires produced huge volumes of smoke that affected regional air quality in the eastern Mediterranean (Poupkou et al., 2014). Figure 10a shows a true colour composite image derived from MODIS Terra imagery acquired on 26 August 2007 (09:35 UTC). The mirrored "S" shaped plume present over the Mediterranean extends across to Tunisia at this time. Figure $10 \mathrm{~b}$ shows a snapshot of the modelled smoke emissions derived from our use of the FRPPIXEL product data set to derive the wildfire emissions, and the use of these within the IFS model (Sect. 5.2). The modelled smoke emission transport captures the spatial structure of the advected smoke plumes very well, consisting of a series of "pulses" of increased AOD that result from the particularly intense emissions during the peak of each diurnal fire cycle. The large region of particularly high AOD on the coast of Libya (L in Fig. 10b, and shown in Fig. 11a and b) results from the intense fire emissions on 25 August, where more than $18 \mathrm{ts}^{-1}$ of biomass were apparently being consumed at the peak intensity. To the west of the main smoke plume, a thinner plume with a lower AOD is evident emanating from fires in Albania. To the east, a smaller plume resulting from wildfires in Turkey is also captured.

It is evident from Fig. 10 that the modelled smoke plumes are offset slightly compared to the actual plumes observed by MODIS, and this is most evident over the Libyan coast. The difference is believed to result from injecting the smoke plume into the lowest atmospheric level, which is an oversimplification as stated earlier since MISR (Multi-angle Imaging SpectroRadiometer)-derived smoke plume heights acquired on 26 August indicated that the plume closest to the wildfires had a height of $2.5 \mathrm{~km}$ (Liu et al., 2009) and CALIPSO lidar observations have detected the plumes at altitudes of $2-3 \mathrm{~km}$ on 25 and 26 August (Turquety et al., 2009). In contrast, the simulated plumes are located predominantly below $1 \mathrm{~km}$ (not shown). Global analysis of MISR data indicates that a large proportion wildfire smoke plume heights remain beneath the boundary layer, although particularly intense fires can inject smoke into the free troposphere (Val Martin et al., 2010; Dirksen et al., 2009; Fromm et al., 2000). Our modelled plume is typically also broader than that observed by MODIS and covers a larger spatial extent. This may result from the relatively coarse spatial resolution used in the model, and comparisons between our simulation and MODIS AOD estimates made on 26 August (DOY 238, Fig. 11a, b) indicate that whilst the broad magnitude of the modelled smoke emission "pulses" are in good agreement with observations, the simulated plume's AOD appears overestimated compared to MODIS. This suggests some inaccuracies remain in the aerosol source modelling, and for example Garcia-Menendez et al. (2014) found modelled $\mathrm{PM}_{2.5}$ concentrations are more sensitive to the injection height parameterisation than to the emissions vertical distribution, due 
a)

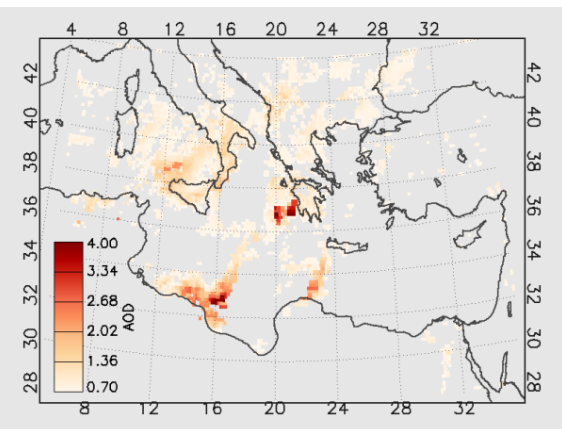

b)

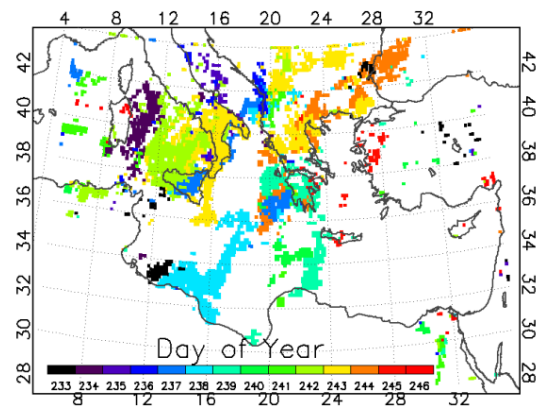

Figure 11. Data extracted for the 2007 Mediterranean mega-fire event from Terra and Aqua MODIS AOD products (a) Maximum value composite of atmospheric AOD developed using Terra and Aqua MODIS observations (MOD04 and MYD04 products) acquired between 21 August and 3 September 2007. Only pixels with an AOD value in excess of 0.7 are shown. (b) Day of the year (DOY) of the highest AOD value shown in (a).

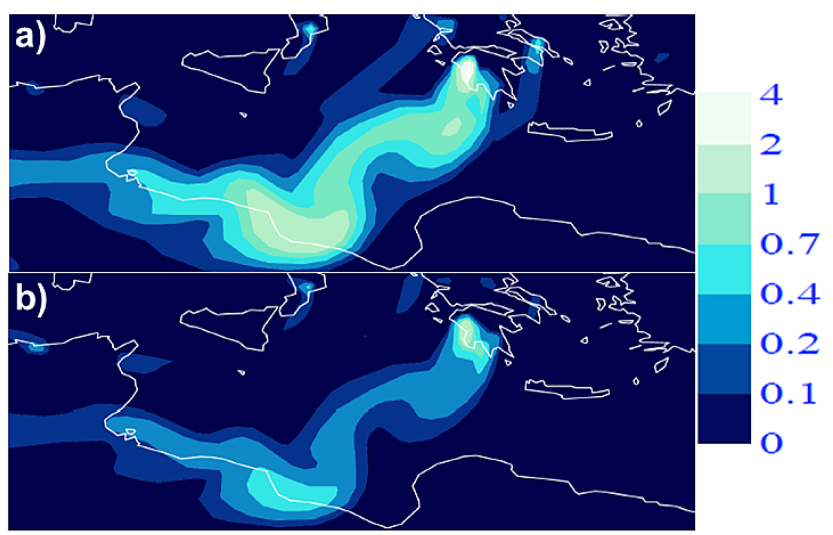

Figure 12. Modelled smoke plume on 26 August (09:35 UTC) calculated using (a) daily, and (b) weekly temporal resolution FRPderived smoke source emissions as described in Sect. 5.4. The blue scale indicates variations in the modelled smoke a AOD at $550 \mathrm{~nm}$. The corresponding modelled AOD obtained using hourly FRP-derived source emissions is shown in Fig. $10 \mathrm{~b}$.

to the diurnal evolution of the planetary boundary layer and local meteorological conditions.

\subsection{Impact of emission fields, temporal resolution}

A number of studies (e.g. Chen et al., 2009; Marlier et al., 2014; Reid et al., 2009; Garcia-Menendez et al., 2014) have found that resolving the diurnal variability of fire emissions has important implications when modelling the emissions' atmospheric transport. We used our study of the Peloponnese fires to address this issue by reducing the temporal resolution of the SEVIRI FRP-derived emissions density fields, from the original $1 \mathrm{~h}$ to 1 day and then 1 week, the latter two being more representative of the global emissions inventories developed using only observations from polar orbiting instruments (van der Werf et al., 2010; Kaiser et al.,
2012; Sofiev et al., 2009). The resulting sensitivity to temporal resolution is illustrated in Fig. 12a and b, which show modelled AOD (at $550 \mathrm{~nm}$ ) on 26 August (09:35 UTC) using the emissions prescribed at a daily and weekly temporal resolution. In both cases, the shape of the modelled Peloponnese smoke plume remains broadly consistent with the hourly simulation of Fig. 10a, although smoke emissions from neighbouring countries are much less pronounced. The Albanian plume is progressively shorter in Fig. 12a and b, whilst some plumes (e.g. those from Turkey to Crete) are missing altogether. Source emissions at weekly temporal resolution (Fig. 12b) remove the daily variability, resulting in lower aerosol amounts at both the source region and over the entire plume. It is also evident that emissions are being generated at incorrect times when using these reduced temporal resolution source data. For example, the daily and weekly simulations have plumes emanating from southern Italy too early, since fires are in fact in reality just developing in the source region (Fig. 12b). Baldassarre et al. (2015) provide further evidence of the importance of the high temporal resolution provided by the SEVIRI FRP-PIXEL data set when modelling smoke transport from individual large fire events.

\subsection{Comparison of in situ and modelled aerosol optical depth}

Section 5.4 has indicated that model simulations using hourly smoke emissions fields improve the representation of both the spatial and temporal evolution of the smoke plumes from the main Mediterranean mega fires of August 2007. However, qualitative comparison to MODIS AOD estimates (Fig. 11a, b) indicated that the plume's modelled AOD was somewhat higher than satellite-derived AOD estimates. Over the same time period as the Peloponnese fires, a series of fires occurred on the Algerian coast (Fig. 13a) whose plumes were detected by the AERONET (Aerosol Robotic Network; Holben et al., 2001) site at Lecce (Italy; $40.35^{\circ} \mathrm{N}, 18.16^{\circ} \mathrm{E}$ ). 
a)
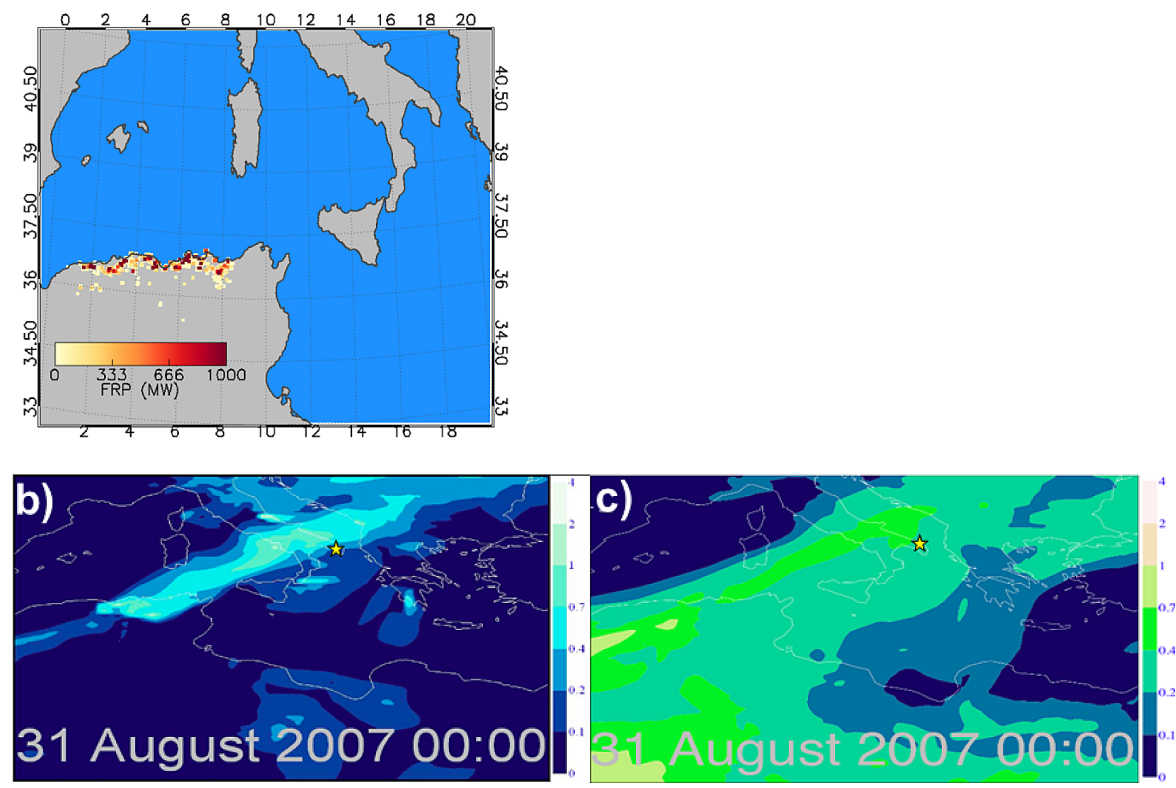

Comparison of model (eyvo) \& MODIS AOT at $550 \mathrm{~nm}$ and L1.5 Aeronet AOT at $500 \mathrm{~nm}$ FC Total FC Dust FC BC+OM Aeronet Total Aeronet Fine MODIS Total

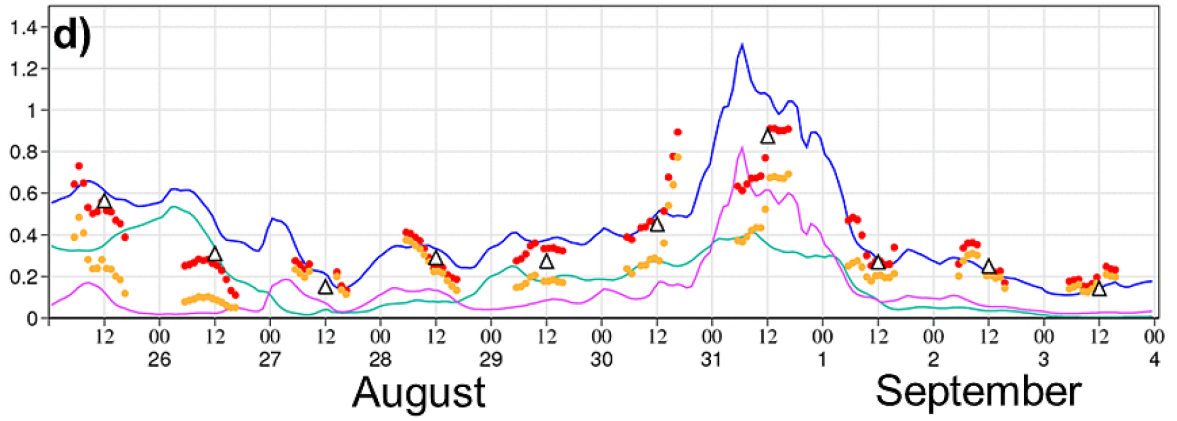

Figure 13. MODIS FRP from the Algerian wildfires (a) between 26 August and 4 September 2007, (b) modelled smoke and (c) modelled dust AOD at $550 \mathrm{~nm}$ on 31 August 2007 (00:00 UTC). (d) time series of daily averaged MODIS total AOD observations (open black triangles), the AERONET observations of total (red circles) and fine-mode AOD (orange circles), modelled total AOD (blue line) and its contributions due to smoke (purple line) and dust (green line). Data sources: MODIS (http://disc1.sci.gsfc.nasa.gov) and AERONET (http://aeronet.gsfc.nasa.gov).

Figure $13 \mathrm{~b}$ and $\mathrm{c}$ show the modelled smoke and dust AOD respectively on 31 August (00:00 UTC) where the former illustrates the smoke plume extension over the AERONET site (yellow star symbol). Figure 13d is a temporal profile of AOD recorded (at $500 \mathrm{~nm}$ ) over Lecce from AERONET observations of total (red circles) and fine-mode (orange circles) AOD, daily averaged MODIS AOD $(550 \mathrm{~nm})$ observations (black triangles) and model simulations of total AOD (blue line). Modelled AOD contributions of smoke (purple line) and dust (green line) to the total AOD are also shown. The MODIS AOD estimates are derived through averaging all observations within the model grid cell. The smoke AOD displays greater short-term variability than does the dust AOD, since the wildfires represent significantly more localised sources than do the regions of dust uplift. The smoke
AOD displays an increase in magnitude from 0.6 to 1.3 between 31 August and 1 September, which occurs $23 \mathrm{~h}$ prior to the peak FRP $(63 \mathrm{GW})$ of the Algerian fires. However, between 27 and 31 August, MODIS detected 330 active fires in southern Italy (Fig. 14) which were greatest in number on 27 (114) and 31 (110) August and which are likely to have contributed to the Algerian smoke plume but which may not all be included in our modelling since the majority $(63 \%)$ had an FRP $<30 \mathrm{MW}$ and so may not be detected by SEVIRI.

Compared to the daily averaged MODIS AOD, our modelled total AOD is typically overestimated by $\sim 20 \%$ during the overpass of the smoke plume (31 August), but the model does capture the temporal trend of the observed AOD rather well. The AERONET AOD data provides a more complete temporal profile than do MODIS' AOD observations, 


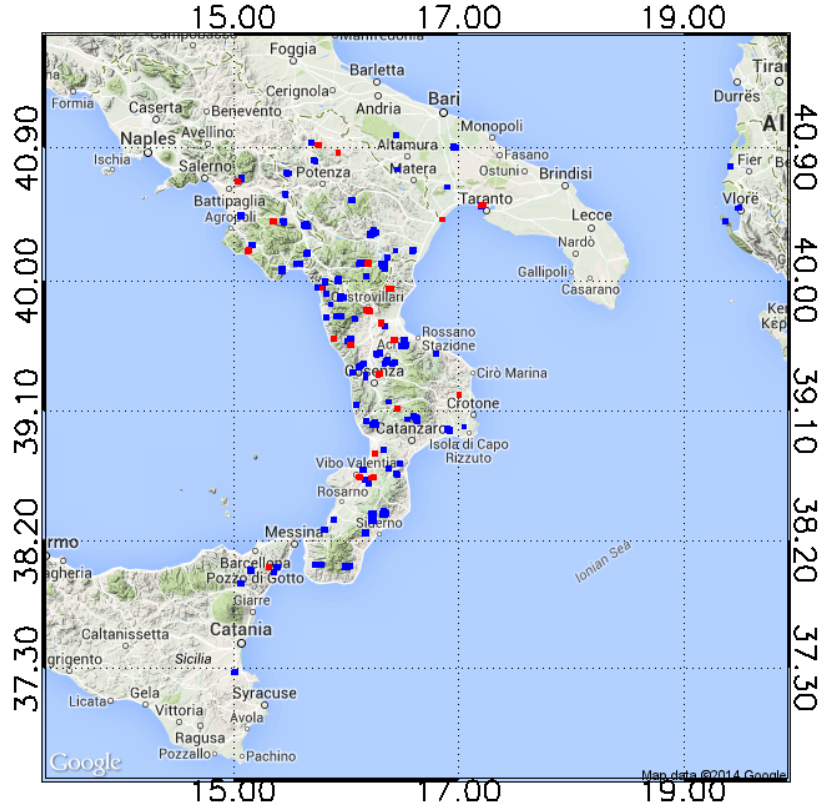

Figure 14. MODIS active fire detections occurring between 27 and 31 August (blue symbols) and 28 and 29 August (red symbols). These fires typically occur downwind of the Algerian smoke plume seen in Fig. 13 and therefore are likely to have contributed to elevated AOD values detected at the Lecce AERONET site.

and our modelled total AOD typically captures these dynamics. However, the onset of increased AOD due to the Algerian fires (30 August) is captured $8 \mathrm{~h}$ earlier by AERONET than by our modelled AOD, whilst the descending limb is temporally coincident between data sets. The former may result from assumptions made regarding the smoke plume injection heights or to shortcomings in the simulations due to increased cloud cover over Algeria on 29 August. It is also possible that, given the rapid rise in AOD in a $3 \mathrm{~h}$ period, this is a localised effect due to small, undetected fires in the vicinity of the AERONET station and which are not represented in our simulation. Between 28 and 29 August, MODIS detected 96 active fires (Fig. 13, red symbols) to the south-west of Lecce and in close proximity to the smoke plume emitted by the Algerian fires, and these are most likely to contribute to the elevated AOD at this time (Fig. 11a and b). In general, the AOD resulting from the use of the SEVIRI FRP-PIXEL product data and the IFS model is overestimated compared to AERONET observations by $10-40 \%$ during the biomass burning plume overpass, and with a discrepancy of $8 \mathrm{~h}$ at the onset of the plume overpass. Clearly we will in future aim to further refine the fire emissions parameterisation, which appears currently to be positively biased relative to the observations. Nevertheless, this case study has demonstrated the clear value of the high temporal frequency SEVIRI-derived FRP observations for large, rapidly varying wildfires such as this.

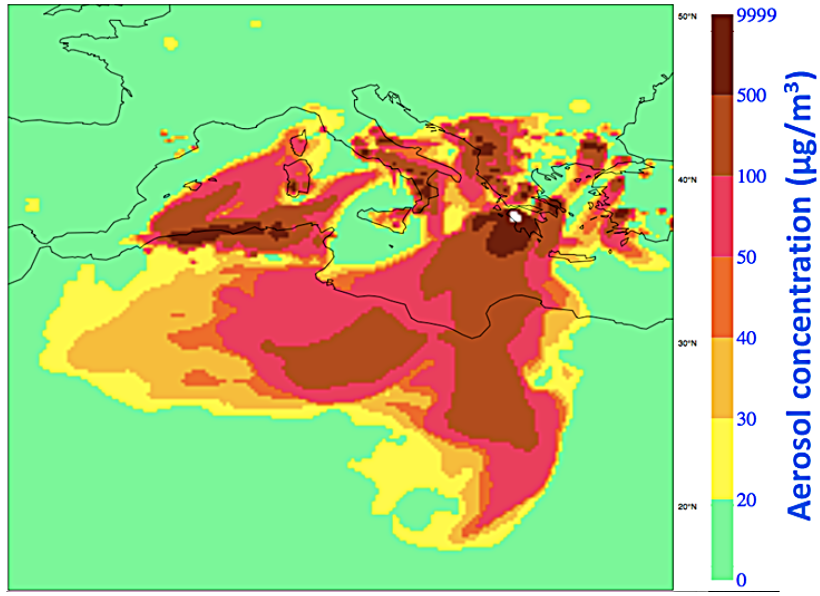

Figure 15. Simulated maximum $24 \mathrm{~h}$ running mean smoke aerosol concentration $\left(\mu \mathrm{g} \mathrm{m}^{-3}\right)$ recorded at the surface between $23 \mathrm{Au}$ gust and 3 September 2007, based on the methodology outlined in Sect. 5.6. The values are an upper limit due to unrealistically low smoke injection height into the atmosphere. The World Health Organisation (WHO) air quality guidelines (WHO, 2006) set a limit of $25 \mu \mathrm{g} \mathrm{m}^{-3}$ for the surface concentration of fine-mode particulate matter $\left(\mathrm{PM}_{2.5}\right)$ averaged over a $24 \mathrm{~h}$ period.

\subsection{Air quality assessment}

The 2007 Mediterranean mega-fire event significantly impacted regional air quality, and fires worldwide are known to have severe health implications for those badly affected by their emissions. Jacobson (2014) estimated that average annual premature mortalities due to biomass burning emissions of $\mathrm{PM}_{2.5}$ and ozone are of the order of $20000(10000$ $30000)$ and $230000(63000-405000)$ respectively, equating to between 5 and $10 \%$ of global mortality due to indoor and outdoor air pollution. One of the primary uses of the CAMS is to forecast regional air quality across Europe, providing rapid and reliable information directly relevant to human health issues, and this includes the consequences of wildfire emissions (Hollingsworth et al., 2008). It is therefore pertinent to assess the significance of our Peloponnese smoke emissions transport simulations in relation to air quality and human health, potentially since Mitsakis et al. (2014) already estimated that over 2000 people were admitted to hospitals and medical centres as a direct result of the Peloponnese fire event, and of these 1100 were due to cardiovascular and respiratory problems. The World Health Organisation (WHO) air quality guidelines (WHO, 2006) in particular set a limit of $25 \mu \mathrm{g} \mathrm{m}^{-3}$ for the concentration of fine-mode particulate matter $\left(\mathrm{PM}_{2.5}\right)$ averaged over a $24 \mathrm{~h}$ period. We estimated concentrations of $\mathrm{PM}_{2.5}$ using our simulated $\mathrm{OM}$ and $\mathrm{BC}$ concentrations in the lowest modelled atmospheric layer and calculated the $24 \mathrm{~h}$ running average for comparison to this WHO threshold. 
Figure 15 shows the distribution of $24 \mathrm{~h}$ mean $\mathrm{PM}_{2.5}$ concentrations modelled between 23 August and 3 September (when the Peloponnese wildfires were at their most intense; Fig. 9a). It is clear that the impacts of the Peloponnese wildfires extend well beyond Greece's national borders and indeed resulted in large parts of the Mediterranean region exceeding the WHO $25 \mu \mathrm{g} \mathrm{m}^{-3} \mathrm{PM}_{2.5}$ concentration threshold by significant margins. In fact, analysis of the spatial distribution of these data with respect to population density (CIESIN and CIAT, 2005) indicated that, for the region shown in Fig. 15, up to 40 million people might have been subject to $\mathrm{PM}_{2.5}$ concentrations exceeding the WHO guidelines. However, it should be stressed that this is an upper limit for the exposure, because our study significantly over-estimates near-surface smoke concentration due to the assumed boundary-layer injection of the emissions. In particular, surface $\mathrm{PM}_{2.5}$ concentrations in regions reasonably close to the source that are well above $100 \mu \mathrm{g} \mathrm{m}^{-3}$ are very likely to be spurious, and Liu et al. (2009) report elevated non-urban values closer to $49 \mu \mathrm{g} \mathrm{m}^{-3}$, albeit still at some distance from the source. Nonetheless, the spatial range of the affected area, and the considerable human health impacts that these type of large wildfire events can have, highlights the necessity of modelling their smoke emissions and forecasting their atmospheric transport in the manner demonstrated here. Through such work, the CAMS and its downstream services aim at improving emergency preparedness through air quality forecasts. Geostationary FRP data are likely to be an important component of this system, particularly so as their high temporal resolution FRP data provides a unique view of the type of individual large mega-fire event studied here, that can impact regional air quality so dramatically over short timescales.

\section{Summary and conclusions}

This work has provided a detailed performance evaluation of the Meteosat SEVIRI FRP products available from the LSA SAF, both the full resolution FRP-PIXEL product and the reduced resolution FRP-GRID product, both available in nearreal time and in archived form (http://landsaf.meteo.pt/). It has also provided a detailed example of use of the former product in characterising the smoke emissions from a large European wildfire event whose smoke significantly affected the Mediterranean region as a whole, and for which we have demonstrated an ability to simulate the atmospheric transport and human health impacts at high temporal resolution.

When evaluated against the MODIS MOD14 and MYD14 active fire products, the active fire pixel detection error of commission of the FRP-PIXEL product is found to be $9 \%$ in the Northern Africa LSA SAF geographic region, and increases to higher values particularly in Europe and South America. The basis of this variation is the combination of SEVIRI's increasing pixel area with view zenith angle away from the sub-satellite point, and the relative proportion of lower intensity and/or smaller fires in the various LSA SAF geographic regions (i.e. their fire regimes). Area-based comparisons indicate that the FRP-PIXEL product underestimates compared to simultaneously collected MODIS FRP of a region by between 35 and $89 \%$, with the variation being again dependent upon the above factors. Underestimation is typically maximised at regions extending towards the edge of the viewing disk, furthest away from the SEVIRI subsatellite point. However, comparison of the FRP of individual fires successfully detected almost simultaneously by both SEVIRI and MODIS indicates a strong agreement between the two FRP measurements, with the FRP-PIXEL product meeting its target accuracy requirements. We find that $76 \%$ of the examined simultaneously detected fire clusters had an FRP from SEVIRI within $30 \%$ of that measured by MODIS, which given the recent quantification of MODIS' FRP uncertainty (Freeborn et al., 2014c) indicates good performance from the FRP-PIXEL product. Overall, minimal bias is seen between the per-fire FRP observations made by the two sensors.

When compared against that of other active fire products derived from the same Meteosat SEVIRI observations, the performance of the operational geostationary fire thermal anomaly (FTA) algorithm used within the FRP-PIXEL product (Wooster et al., 2015) compares favourably. During our comparison to MODIS, the SEVIRI WFABBA, FDeM and FIR products from Prins et al. (1998), Amraoui et al. (2010) and Joro et al. (2008) respectively have higher active fire errors of omission, varying between 84 and $95 \%$, as compared to the $77 \%$ of the FRP-PIXEL product. However, these alternative SEVIRI-derived active fire products do have lower errors of commission than the FRP-PIXEL product when compared to MODIS, ranging between 5 and $6 \%$ (the FRPPIXEL product has a $13 \%$ commission error). The FTA errors of commission are currently being reduced by reinclusion of the dynamic spatial thresholding parameters described in Sect. 3.2.2 that were removed from the operational FTA algorithm for computational speed but included in the original Roberts and Wooster (2008) prototype.

The Level-3 FRP-GRID product accumulates a series of FRP-PIXEL products and provides regional estimates of mean FRP at an hourly temporal resolution and a 5.0 $0^{\circ}$ spatial resolution. These estimates come already adjusted for cloud cover and for the impact of the low spatial resolution detection bias that results in SEVIRI failing to detect the lower FRP active fire pixels. Our evaluation indicates good performance of these bias corrections at the hourly, 5.0 $0^{\circ}$ product resolution, but evaluation of accumulated data against summed weekly MODIS FRP over the four LSA SAF geographic regions indicates that the FRP-GRID product underestimates total FRP at this scale. This largely results from the difficulty in accounting for situations where MODIS detects fire activity in a grid cell whilst SEVIRI does not, so the bias corrections remain inactive. We provide herein some 
additional adjustment factors for those wishing to use the SEVIRI FRP-GRID data sets at this type of scale.

Despite their coarse spatial resolution limitations, the FRP products available from geostationary satellites offer an unprecedented high temporal resolution for studying wildfire emissions. This is a key advantage when using such data to parameterise wildfire smoke emissions within atmospheric transport models (Reid et al., 2009). Here we use a version of the FRP-PIXEL product to characterise the smoke emissions from the August 2007 Peloponnese wildfires. The resulting emissions fields are used within ECMWF's IFS to model the smoke emissions transport and, in particular, the black carbon and organic carbon aerosols and the resulting aerosol optical depth and $\mathrm{PM}_{2.5}$ surface concentrations. Our results support the findings of other recent studies (e.g. GarciaMenendez et al., 2014; Marlier et al., 2014) in that higher temporal resolution smoke emissions estimates provide increased fidelity in the resulting smoke plume aerial distribution and optical thickness metrics than do simulations conducted using daily or weekly temporal resolution data. Visual assessment of the modelled plume's spatial distribution against simultaneous MODIS optical imagery shows good agreement, but the modelled plume is slightly offset from the observations, which is believed to result from injecting the plume into the lowest atmospheric layer (whereas in reality it would have been lofted to higher altitudes). Quantitative comparisons between our modelled AOD and the coincident MODIS- and AERONET-derived AOD values indicate that modelled AODs are overestimated by $\sim 20-30 \%$. Further research into model parameterisation (e.g. injection height) and the aerosol emission factors used is required to investigate this bias, particularly so as it is likely that we underestimate fuel consumption due to SEVIRI MWIR channel saturation during this extreme wildfire event. The European Union (EU) has recently signed a delegation agreement with ECMWF to provide the services implemented in MACC, including the FRP-based GFAS (Kaiser et al., 2012), in an operational manner until at least 2020. This includes on-going developments of GFAS which aim at providing emission estimates with an hourly temporal resolution by combining FRP observations from both polar orbiting and geostationary satellites. Key pre-requisites are the implementation of a model for the diurnal cycle of FRP (Andela et al., 2015) and a suitable bias correction for geostationary FRP products to account for the omission of low intensity fires, building on the simple linear bias corrections applied currently in the FRPGRID products.

Acknowledgements. Funding for this work came from the UK NERC National Centre for Earth Observation (NCEO), from the LSA SAF project, from EUMETSAT and the EU H2020 project MACC-III (contract no. 633080). SEVIRI data were kindly provided under an ESA/EUMETSAT AO, the MODIS data were provided by the NASA EDC DAACS and the European Forest Fire Information System (EFFIS; http://effis.jrc.ec.europa.eu) of the
European Commission Joint Research Centre provided burned area data. The GOES $\backslash$ SEVIRI WFABBA data were kindly provided by the Cooperative Institute for Meteorological Satellite Studies (CIMSS) within the Space Science and Engineering Center (SSEC) at University of Wisconsin (UW-Madison) as a collaborative effort between NOAA/NESDIS/STAR and UW-CIMSS personnel. The SEVIRI FRP products were provided by the LSA SAF (http://landsaf.meteo.pt/), and the FDeM product was provided by Carlos C. DaCamara and Sofia Ermida at Universidade de Lisboa (http://www.fc.ul.pt/). The FIR fire products were obtained from the EUMETSAT EO portal (https://eoportal.eumetsat.int/). The authors would also like to thank Allessio Lattanzio (EUMETSAT), Isabel Trigo (LSASAF) and Yves Govaerts (Rayference) for the assistance and advice provided during this study.

Edited by: V.-H. Peuch

\section{References}

Amraoui, M., DaCamara, C. C., and Pereira, J. M. C.: Detection and monitoring of African vegetation fires using MSG-SEVIRI imagery, Rem. Sens. Environ., 114, 1038-1052, 2010.

Andela, N., Kaiser, J. W., van der Werf, G. R., and Wooster, M. J.: New fire diurnal cycle characterizations to improve fire radiative energy assessments made from MODIS observations, Atmos. Chem. Phys., 15, 8831-8846, doi:10.5194/acp-15-88312015, 2015.

Andreae, M. O. and Merlet, P.: Emission of trace gases and aerosols from biomass burning, Global Biogeochem. Cycles, 15, 995966, 2001.

Baldassarre, G., Pozzoli, L., Schmidt, C. C., Unal, A., Kindap, T., Menzel, W. P., Whitburn, S., Coheur, P.-F., Kavgaci, A., and Kaiser, J. W.: Using SEVIRI fire observations to drive smoke plumes in the CMAQ air quality model: a case study over Antalya in 2008, Atmos. Chem. Phys., 15, 8539-8558, doi:10.5194/acp-15-8539-2015, 2015.

Berk, A., Anderson, G. P., Acharya, P. K., Bernstein, L. S., Muratov, L., Lee, J., Fox, M., Adler-Golden, S. M., Chetwynd, J. H., Hoke, M. L., Lockwood, R. B., Gardner, J. A., Cooley, T. W., Borel, C. C., and Lewis, P. E.: MODTRAN (TM) 5, a reformulated atmospheric band model with auxiliary species and practical multiple scattering options: Update, Algorithms and Technologies for Multispectral, Hyperspectral, and Ultraspectral Imagery XI, 5806, 662-667, 2005.

Calle, A., Casanova, J.-L., and Gonzales-Alonso, F.: Impact of point spread function of MSG SEVIRI on active fire detections, Int. J Rem. Sens., 30, 4567-4579, 2009.

Center for International Earth Science Information Network (CIESIN) and Centro Internacional de Agricultura Tropical (CIAT): Gridded Population of the World Version 3 (GPWv3), Palisades, NY, CIESIN Columbia University, available at: http://sedac.ciesin.columbia.edu/gpw/index.jsp (last access: 10 November 2015), 2005.

Chen, Y., Li, Q., Randerson, J. T., Lyons, E. A., Kahn, R. A., Nelson, D. L., and Diner, D. J.: The sensitivity of CO and aerosol transport to the temporal and vertical distribution of North American boreal fire emissions, Atmos. Chem. Phys., 9, 6559-6580, doi:10.5194/acp-9-6559-2009, 2009. 
Csiszar, I., Schroeder, W., Giglio, L., Ellicott, E., Vadrevu, K. P., Justice, C. O., and Wind, B.: Active fires from Suomi NPP Visible Infrared Imaging Radiometer Suite : Product status and fire evaluation results, J. Geophys. Res.-Atmos., 119, 803-816, 2014.

Derrien, M. and Le Gleau, H.: MSG/SEVIRI cloud mask and type from SAFNWC, Int. J. Rem. Sens., 26, 4707-4732, 2005.

Dirksen, R. J,, Boersma, K. F, de Laat, J, Stammes, P., van der Werf, G. R., Martin, M. V., and Kelder, H. M.: An aerosol boomerang: rapid around-the-world transport of smoke from the December 2006 Australian forest fires observed from space, J. Geophys. Res., 114, D2116, doi:10.1029/2009JD012360, 2009.

Dozier, J.: A method for satellite identification of surface temperature fields of sub-pixel resolution, Rem. Sens. Environ., 11, 221229, 1981.

Ellicott, E., Vermote, E., Giglio, L., and Roberts, G.: Estimating biomass consumed from fire using MODIS FRE, Geophys. Res. Lett., 36, L13401, doi:10.1029/2009GL038581, 2009.

EUMETSAT: Active Fire Monitoring with MSG, Algorithm Theoretical Basis Document, EUM/MET/REP/07/0170, Darmstadt, Germany, 2007.

European Commission: Forest Fires in Europe 2009, EUR 24502 EN, Office for Official Publications of the European Communities, Luxembourg, p. 81, 2010.

Freeborn, P. H., Wooster, M. J., Hao, W. M., Ryan, C. A., Nordgren, B. L., Baker, S. P., and Ichoku, C.: Relationships between energy release, fuel mass loss, and trace gas and aerosol emissions during laboratory biomass fires, J. Geophys. Res., 113, D01301, doi:10.1029/2007JD008679, 2008.

Freeborn, P. H., Wooster, M. J., Roberts, G., Malamud, B. D., and $\mathrm{Xu}, \mathrm{W}$.: Development of a virtual active fire product for Africa through a synthesis of geostationary and polar orbiting satellite data, Rem. Sens. Environ., 113, 1700-1711, 2009.

Freeborn, P. H., Wooster, M. J., and Roberts, G.: Addressing the spatiotemporal sampling design of MODIS to provide estimates of the fire radiative energy emitted from Africa, Rem. Sens. Environ., 115, 475-489, 2011.

Freeborn, P. H., Cochrane, M. A., and Wooster, M. J.: A decade long, multi-scale map comparison of fire regime parameters derived from three publically available satellite-based fire products: a case study in the Central African Republic, Rem. Sens., 6, 4061-4089, 2014a.

Freeborn, P. H., Wooster, M. J., Roberts, G., and Xu, W.: Evaluating the SEVIRI Fire Thermal Anomaly Detection Algorithm across the Central African Republic Using the MODIS Active Fire Product, Remote Sens., 6, 1890-1917, doi:10.3390/rs6031890, 2014b.

Freeborn, P. H., Wooster, M. J., Roy, D. P., and Cochrane, M. A.: Quantification of MODIS fire radiative power (FRP) measurement uncertainty for use in satellite-based active fire characterization and biomass burning estimation, Geophys. Res. Lett., 41, 1988-1994, 2014c.

Fromm, M., Jerome, A., Hoppel, K., Hornstein, J., Bevilacqua, R., Shettle, E., Servranckx, R., Zhanqing, L., and Stocks, B.: Observations of boreal forest fire smoke in the stratosphere by POAM III, SAGE II, and lidar in 1998, Geophys. Res. Lett., 27, 14071410, doi:10.1029/1999GL011200, 2000.

Garcia-Menendez, F., Hu, Y., and Odman, M. T.: Simulating smoke transport from wildland fires with a regional-scale air quality model: Sensitivity to spatiotemporal allocation of fire emissions, Sci. Tot. Environ., 493, 544-553, 2014.

Georgiev, C. G. and Stoyanova, J. S.: Parallel use of SEVIRI LSA SAF FRP and MPEF FIR products for fire detection and monitoring, 2013 EUMETSAT Meteorological Satellite Conference, 19th American Meteorological Society, AMS Satellite Meteorology, Oceanography and Climatology Conference, 16-20 September 2013, Vienna, Austria, ISSN 1011-3932, 2013.

Giglio, L., Descloitres, J., Justice, C. O., and Kaufman, Y. J.: An enhanced contextural fire detection algorithm for MODIS, Rem. Sens. Environ., 87, 273-282, 2003.

Gitas, I. Z., Polychronaki, A., Katagis, T., and Mallinis, G.: Contribution of remote sensing to disaster management activities: A case study of the large fires in the Peloponnese, Greece, Int. J. Rem. Sens., 29, 1847-1853, doi:10.1080/01431160701874553, 2008.

Govaerts, Y.: RTMOM V0B.10 Evaluation report, report EUM/MET/DOC/06/0502, EUMETSAT, 2006, 2226, 2006.

Guan, H., Chatfield, R. B., Freitas, S. R., Bergstrom, R. W., and Longo, K. M.: Modeling the effect of plume-rise on the transport of carbon monoxide over Africa with NCAR CAM, Atmos. Chem. Phys., 8, 6801-6812, doi:10.5194/acp-8-6801-2008, 2008.

Holben, B. N., Smirnov, A., Eck, T. F., Slutsker, I., Abuhassan, N., Newcomb, W. W., Schafer, J. S., Tanre, D., Chatenet, B., and Lavenu, F.: An emerging ground-based aerosol climatology: Aerosol optical depth from AERONET, J. Geophys. Res.Atmos., 106, 12067-12097, doi:10.1029/2001JD900014, 2001.

Hollingsworth, A., Engelen, R. J., Benedetti, A., Dethof, A., Flemming, J., Kaiser, J. W., Morcrette, J.-J., Simmons, A. J., Textor, C., Boucher, O., Chevallier, F. Rayner, P., Elbern, H., Eskes, H., Granier, C., Peuch, V.-H., Rouil, L., and Schultz, M. G.: Toward a Monitoring and Forecasting System For Atmospheric Composition: The GEMS Project, B. Am. Meteorol. Soc., 89, 1147-1164, doi:10.1175/2008BAMS2355.1, 2008.

Ichoku, C. and Kaufman, Y. J.: A method to derive smoke emission rates from MODIS fire radiative energy measurements, IEEE T. Geosci. Rem. Sens., 43, 2636-2649, 2005.

Jacobson, M. Z.: Effects of biomass burning on climate, accounting for heat and moisture fluxes, black and brown carbon, and cloud absorption effects, J. Geophys. Res.-Atmos., 119, 89809002, doi:10.1002/2014JD021861, 2014.

Jenkins, B. M., Baxter, L. L., Miles Jr., T. R., and Miles, T. R.: Combustion properties of biomass, Fuel Processing Technol., 54, 17-46, 1998.

Joro, S., Samain, O., Yildirim, A., van de Berg, L., and Lutz, H. J.: Towards an improved active fire monitoring product for MSG satellites. www.eumetsat.int/cs/idcplg?IdcService=GET_ FILE\&dDocName=pdf_conf_p_s8_47_joro_v\&allowInterrupt= $1 \&$ noSaveAs $=1 \&$ RevisionSelectionMethod=LatestReleased, 2008.

Justice, C. O., Vermote, E., Townshend, J. R. G., DeFries, R., Roy, D. P., Hall, D. K., Salomonson, V. V., Privette, J. L., Riggs, G., Strahler, A., Lucht, W., Myneni, R. B., Knyazikhin, Y., Running, S. W., Nemani, R. R., Wan, Z., Huete, A. R., van Leewen, W., Wolfe, R. E., Giglio, L., Muller, J-P., Lewis, P., and Barnesly, M. J.: The Moderate Resolution Imaging Spectrometer (MODIS): Land Remote Sensing for Global Change Research, IEEE T. Geosci. Rem. Sens., 36, 1228-1249, 1998. 
Kaiser, J. W., Boucher, O., Doutriaux-Boucher, M., Flemming, J., Govaerts, Y. M., Gulliver, J., Heil, A., Jones, L., Lattanzio, A., Morcrette, J.-J., Perrone, M. R., Razinger, M., Roberts, G., Schultz, M. G., Simmons, A. J., Suttie, M., and Wooster, M. J.: Smoke in the air, ECMWF Newsletter, 119, 9-15, European Centre for Medium-range Weather Forecasts, 2009a.

Kaiser, J. W., Suttie, M., Flemming, J., Morcrette, J.-J., Boucher, O., and Schultz, M. G.: Global real-time fire emission estimates based on space-borne fire radiative power observations, AIP Conference Proceedings, 1100, 645-648, 2009b.

Kaiser, J. W., Heil, A., Andreae, M. O., Benedetti, A., Chubarova, N., Jones, L., Morcrette, J.-J., Razinger, M., Schultz, M. G., Suttie, M., and van der Werf, G. R.: Biomass burning emissions estimated with a global fire assimilation system based on observed fire radiative power, Biogeosciences, 9, 527-554, doi:10.5194/bg-9-527-2012, 2012.

Kaufman, Y. J. and Remer, L. A.: Detection of forests using Mid-IR reflectance: An application for aerosol studies. IEEE T. Geosci. Rem. Sens., 32, 672-683, 1994.

Kaufman, Y. J., Remer, L., Ottmar, R., Ward, D., Rong-R, L., Kleidman, R., Frase, R., Flynn, L., McDougal, D., and Shelton, G.: Relationship between remotely sensed fire intensity and rate of emission of smoke: SCAR-C experiment, in: Global biomass burning, edited by: Levine, J., 685-696, MIT Press, MA, 1996.

Kaufman, Y. J., Justice, C. O., Flynn, L. P., Kendall, J. D., Prins, E. M., Giglio, L., Ward, D. E., Menzel, W. P., and Setzer, A. W.: Potential global fire monitoring from EOS-MODIS, J. Geophys. Res., 103, 32215-32238, 1998

Koutsias, N., Arianmoutsou, M., Kallimanis, A. S., Mallinis, G., Halley, J. M., and Dimopoulos, P.: Where did the fires burn in Peloponnese, Greece the summer of 2007? Evidence for a synergy of fuel and weather, Agric. For. Meteorol., 156, 41-53, 2012.

Leung, F.-Y. T., Logan, J. A., Park, R., Hyer, E., Kasischke, E., Streets, D., and Yurganov, L.: Impacts of enhanced biomass burning in the boreal forests in 1998 on tropospheric chemistry and the sensitivity of model results to the injection height of emissions, J. Geophys. Res., 112, D10313, doi:10.1029/2006JD008132, 2007.

Li, Z., Kaufman, Y. J., Ichoku, C., Fraser, R., Trishchenko, A., Giglio, L., and Yu, X.: A review of AVHRR-based active fire detection algorithms: Principles, limitations, and recommendations, Global and regional vegetation fire monitoring from space, planning and coordinated international effort, Academic Publishing, The Hague, 199-225 p., 2001.

Liu, Y., Kahn, R. A., Chaloulakou, A., and Koutrakis, P.: Analysis of the impact of the forest fires in August 2007 on air quality of Athens using multi-sensor aerosol remote sensing data, meteorology and surface observations, Atmos. Environ., 43, 33103318, 2009.

Marlier, M. E., Voulgarakis, A., Shindell, D. T., Faluvegi, G., Henry, C. L., and Randerson, J. T.: The role of temporal evolution in modeling atmospheric emissions from tropical fires, Atmos. Environ., 89, 158-168, doi:10.1016/j.atmosenv.2014.02.039, 2014.

Matson, M.: Identification of subresolution high temperature sources using a thermal IR sensor, Photogramm. Eng. Rem. S., 47, 1311-1318, 1981.

Mitsakis, E., Stamos, I., Panakinolaou, A., Aifadopoulou, G., and Kontoes, H.: Assessment of extreme weather events on transport networks : case study of the 2007 wildfires in Peloponnesus, Nat. Hazards, 72, 87-107, doi:10.1007/s11069-013-0896-3, 2014.

Mitsopoulos, I. D. and Dimitrakopoulos, A. P.: Estimation of canopy fuel chracteristics of Aleppo pine (Pinus halepensis Mill.) forests in Greece based on common stand parameters, European J. For. Res., 133, 73-79, doi:10.1007/s10342-013-0740-z, 2013.

Morcrette, J.-J., Jones, L., Kaiser, J. W., Benedetti, A., and Boucher, O.: Toward a forecast of aerosols with the ECMWF Integrated Forecast System, ECMWF Newsletter, No. 114, ECMWF, Reading, UK, 2008.

Mu, M., Randerson, J. T., van der Werf, G. R., Giglio, L., Kasibhatla, P., Morton, D., Collatz, G. J., DeFries, R. S., Hyer, E. J., Prins, E. M., Griffith, D. W. T., Wunch, D., Toon, G. C., Sherlock, V., and Wennberg, P. O.: Daily and 3-hourly variability in global fire emissions and consequences for atmospheric model predictions of carbon monoxide, J. Geophys. Res.-Atmos., 116, D24303, doi:10.1029/2011JD016245, 2011.

Paugam, R., Wooster, M., Atherton, J., Freitas, S. R., Schultz, M. G., and Kaiser, J. W.: Development and optimization of a wildfire plume rise model based on remote sensing data inputs - Part 2, Atmos. Chem. Phys. Discuss., 15, 9815-9895, doi:10.5194/acpd-15-9815-2015, 2015a.

Paugam, R., Wooster, M., Freitas, S. R., and Val Martin, M.: A review of approaches to estimate wildfire plume injection height within large scale atmospheric chemical transport models - Part 1, Atmos. Chem. Phys. Discuss., 15, 9767-9813, doi:10.5194/acpd-15-9767-2015, 2015b.

Pereira, G., Shimabukuro, Y. E., Moraes, E. C., Freitas, S. R., Cardozo, F., S., and Longo, K. M.: Monitoring the transport of biomass burning emission in South America, Atmos. Pollut Res., 3, 247-254, 2011.

Petitcolin, F. and Vermote, E.: Land surface reflectance, emissivity and temperature from MODIS middle and thermal infrared data, Rem. Sens. Environ., 82, 112-134, 2002.

Petrenko, M., Kahn, R., Chin, M., Soja, A., Kucsera, T., and Harshvardhan: The use of satellite-measured aerosol optical depth to constrain biomass burning emissions source strength in the global model GOCART, J. Geophys. Res., 117, D22204, doi:10.1029/2012JD017870, 2012.

Poupkou, A., Markakis, K., N..Liora, Giannaros, T. M., Zanis, P., Im, U., Daskalakis, N., Myriokefalitakis, S., Kaiser, J. W., Melas, D., Kanakidou, M., Karacostas, T., and Zerefos, C.: A modeling study of the impact of the 2007 Greek forest fires on the gaseous pollutant levels in the Eastern Mediterranean, Atmos. Environ., 148, 1-17, 2014.

Prins, E. M. and Menzel, W. P.: Trends in South American biomass burning with the GOES visible infrared spin scan radiometer atmospheric sounder from 1983 to 1991, J. Geophys. Res., 99, 16719-16735, 1994.

Prins, E. M., Felts, J. M., Menzel, W. P., and Ward, D. E.: An overview of GOES-8 diurnal fire and smoke results for SCAR-B and 1995 fire season in South America, J. Geophys. Res., 103, 31821-31835, 1998.

Reid, J. S., Prins, E. M., Westphal, D. L., Schmidt, C. C., Richardson, K. A., Christopher, S. A., Eck, T. F., Reid, E. A., Curtis, C. A., and Hoffman, J. P.: Real-time monitoring of South American smoke particle emissions and transport using a coupled remote sensing/box-model approach, Geophys. Res. Lett., 31, L06107, doi:10.1029/2003GL018845, 2004. 
Reid, J. S., Hyer, E. J., Prins, E. M., Westphal, D. L., Zhang, J., Wang, J., Christopher, S. A., Curtis, C. A., Schmidt, C. C., Eleuterio, D. P., Richardson, K. A., and Hoffman, J. P.: Global monitoring and forecasting of biomass-burning smoke: description of and lessons from the Fire Locating and Modeling of Burning Emissions (FLAMBE) program, IEEE Journal of Selected Topics in Applied Earth Observations and Remote Sensing, 2, 144-162, 2009.

Roberts, G. and Wooster, M. J.: New perspectives on Africa biomass burning dynamics, EOS Transactions American Geophysical Union, 88, 369-370, 2007.

Roberts, G. and Wooster, M. J.: Fire Detection and Fire Characterization over Africa using Meteosat SEVIRI, IEEE T. Geosci. Remote Sens., 48, 1200-1219, 2008.

Roberts, G. and Wooster, M. J.: Development of a multi-temporal Kalman filter approach to geostationary active fire detection and fire radiative power (FRP) estimation, Rem. Sens. Environ., 152, 392-412, doi:10.1016/j.rse.2014.06.020, 2014.

Roberts, G., Wooster, M. J., Perry, G. L. W., Drake, N., Rebelo, L.M., Dipotso, F.: Retrieval of biomass combustion rates and totals from fire radiative power observations: Application to southern Africa using geostationary SEVIRI imagery, J. Geophys. Res., 110, D21111, doi:10.1029/2005JD006018, 2005.

Roberts, G., Wooster, M. J., and Lagoudakis, E.: Annual and diurnal african biomass burning temporal dynamics, Biogeosciences, 6 , 849-866, doi:10.5194/bg-6-849-2009, 2009.

Roberts, G., Wooster, M. J., Freeborn, P. H., and Xu, W.: Integration of geostationary FRP and polar-orbiting burned area datasets for an enhanced emissions inventory, Rem. Sens. Environ., 115, 2047-2061, doi:10.1016/j.rse.2011.04.006, 2011.

Roy, D. P., Jin, Y., Lewis, P. E., and Justice, C. O.: Prototyping a global algorithm for systematic fire-affected area mapping using MODIS time series data, Rem. Sens. Environ., 97, 137-162, 2005.

Schroeder, W., Prins, E., Giglio, L., Csiszar, I., Schmidt, C., Morisette, J., and Morton, D.: Validation of GOES and MODIS active fire detection products using ASTER and ETM+ data, Rem. Sens. Environ., 112, 2711-2726, 2008.

Schroeder, W., Oliva, P., Giglio, L., and Csiszar, I. A.: The New VIIRS $375 \mathrm{~m}$ active fire detection data product: Algorithm description and initial assessment, Rem. Sens. Environ., 143, 8596, 2014.

Seiler, W. and Crutzen, P. J.: Estimates of gross and net fluxes of carbon between the biosphere and the atmosphere from biomass burning, Clim. Change, 2, 207-247, 1980.

Sofiev, M., Vankevich, R., Lotjonen, M., Prank, M., Petukhov, V., Ermakova, T., Koskinen, J., and Kukkonen, J.: An operational system for the assimilation of the satellite information on wildland fires for the needs of air quality modelling and forecasting, Atmos. Chem. Phys., 9, 6833-6847, doi:10.5194/acp-9-68332009, 2009.

Sofiev, M., Ermakova, T., and Vankevich, R.: Evaluation of the smoke-injection height from wild-land fires using remote-sensing data, Atmos. Chem. Phys., 12, 1995-2006, doi:10.5194/acp-12-1995-2012, 2012.

Theoharatos, G., Pantavou, K., Mavrakis, A., Spanou, A., Katavoutas, G., Efstathiou, P., Mpekas, P., and Asimakopoulos, D.: Heat waves observed in 2007 in Athens, Greece: Synoptic conditions, bioclimatological assessment, air quality levels and health effects, Environ. Res., 110, 152-161, 2010.

Tjemkes, S. A. and Schmetz, J.: Synthetic satellite radiances using the radiance sampling method, J. Geophys. Res., 102, 1807$1818,1997$.

Tsyro, S., Simpson, D., Tarrason, L., Klimont, Z., Kupianen, K., Pio, C., and Yttri, K. E.: Modeling of elemental carbon over Europe, J. Geophys. Res.-Atmos., 112, D23S19, doi:10.1029/2006JD008164, 2007.

Turquety, S., Hurtmans, D., Hadji-Lazaro, J., Coheur, P.-F., Clerbaux, C., Josset, D., and Tsamalis, C.: Tracking the emission and transport of pollution from wildfires using the IASI CO retrievals: analysis of the summer 2007 Greek fires, Atmos. Chem. Phys., 9, 4897-4913, doi:10.5194/acp-9-4897-2009, 2009.

Turquety, S., Menut, L., Bessagnet, B., Anav, A., Viovy, N., Maignan, F., and Wooster, M.: APIFLAME v1.0: high-resolution fire emission model and application to the Euro-Mediterranean region, Geosci. Model Dev., 7, 587-612, doi:10.5194/gmd-7-5872014, 2014.

Val Martin, M., Logan, J. A., Kahn, R. A., Leung, F.-Y., Nelson, D. L., and Diner, D. J.: Smoke injection heights from fires in North America: analysis of 5 years of satellite observations, Atmos. Chem. Phys., 10, 1491-1510, doi:10.5194/acp-10-14912010, 2010.

van der Werf, G. R., Randerson, J. T., Giglio, L., Collatz, G. J., Kasibhatla, P. S., and Arellano Jr., A. F.: Interannual variability in global biomass burning emissions from 1997 to 2004, Atmos. Chem. Phys., 6, 3423-3441, doi:10.5194/acp-6-3423-2006, 2006.

van der Werf, G. R., Randerson, J. T., Giglio, L., Collatz, G. J., Mu, M., Kasibhatla, P. S., Morton, D. C., DeFries, R. S., Jin, Y., and van Leeuwen, T. T.: Global fire emissions and the contribution of deforestation, savanna, forest, agricultural, and peat fires (19972009), Atmos. Chem. Phys., 10, 11707-11735, doi:10.5194/acp10-11707-2010, 2010.

Veraverbeke, S., Lhermitte, S., Verstraeten, W. W., and Goossens, R.: The temporal dimension of differenced Normalised Burn Ratio (dNBR) fire/burn severity studies: The case of the large 2007 Peloponnese wildfires in Greece, Rem. Sens. Environ., 114, 2548-2563, doi:10.1016/j.rse.2010.05.029, 2010.

Vermote, E., Ellicott, E., Dubovik, O., Lapyonok, T., Chin, M., Giglio, G., and Roberts, G.: An approach to estimate global biomass burning emissions of Organic and Black Carbon from MODIS Fire Radiative Power, J. Geophys. Res., 114, D18205, doi:10.1029/2008JD011188, 2009.

Verroios, G. and Georgiadis, T.: Aleppo pine forests of northern and western Peloponnisos (southern Greece): Plant communities and diversity, Plant Biosyst., 145, 606-619, 2011.

World Health Organisation (WHO): Air quality guidelines for particulate matter, ozone, nitrogen dioxide and sulphur dioxide, WHO/SDE/PHE/OEH/06.02, World Health Organization, WHO Press, Geneva, Switzerland, 2006.

Wooster, M. J., Zhukov, B., and Oertel, D.: Fire radiative energy for quantitative study of biomass burning: derivation from the BIRD experimental satellite and comparison to MODIS fire products, Rem. Sens. Environ., 86, 83-107, 2003.

Wooster, M. J., Roberts, G., Perry, G. L. W., and Kaufman, Y. J.: Retrieval of biomass combustion rates and totals from fire radiative power observations: FRP derivation and calibration relationships 
between biomass consumption and fire radiative energy release, J. Geophys. Res., 110, D24311, doi:10.1029/2005JD006318, 2005.

Wooster, M. J., Xu, W., and Nightingale, T.: Sentinel-3 SLSTR active fire detection and FRP product: Pre-launch algorithm development and performance evaluation using MODIS and ASTER datasets, Rem. Sens. Environ., 120, 236-254, 2012.

Wooster, M. J., Roberts, G., Freeborn, P. H., Xu, W., Govaerts, Y., Beeby, R., He, J., Lattanzio, A., Fisher, D., and Mullen, R.: LSA SAF Meteosat FRP products - Part 1: Algorithms, product contents, and analysis, Atmos. Chem. Phys., 15, 13217-13239, doi:10.5194/acp-15-13217-2015, 2015.

Xu, W., Wooster, M. J., Roberts, G., and Freeborn, P.: New GOES imager algorithms for cloud and active fire detection and fire radiative power assessment across North, South and Central America, Rem. Sens. Environ., 114, 1876-1895, 2010.

Xu, W., Wooster, M. J., Roberts, G., and Freeborn, P.: New GOES imager algorithms for cloud and active fire detection and fire radiative power assessment across North, South and Central America, Rem. Sens. Environ., 114, 1876-1895, 2010.
Yang, E.-S., Christopher, S. A., Kondragunta, S., and Zhang, X.: Use of hourly Geostationary Operational Environmental Satellite (GOES) fire emissions in a Community Multiscale Air Quality (CMAQ) model for improving surface particulate matter predictions, J. Geophys. Res.-Atmos., 116, D04303, doi:10.1029/2010JD014482, 2011.

Zhang, X., Kondragunta, S., Ram, J., Schmidt, C., and Hung, H.-C.: Near-real-time global biomass burning emissions product from geostationary satellite constellation, J. Geophys. Res.-Atmos., 117, D14201, doi:10.1029/2012JD017459, 2012.

Zhukov, B., Lorenz, E., Oertel, D., Wooster, M., and Roberts, G.: Spaceborne detection and characterisation of fires during the bi-spectral infrared detection (BIRD) experimental small satellite mission (2001-2004), Rem. Sens. Environ., 100, 29-51, doi:10.1016/j.rse.2005.09.019, 2006. 